\title{
Adult Neural Precursor Cells from the Subventricular Zone Contribute Significantly to Oligodendrocyte Regeneration and Remyelination
}

\author{
Yao Lulu Xing, ${ }^{1,2}$ Philipp T. Röth, ${ }^{1,2}$ Jo Anne S. Stratton, ${ }^{1,3}$ Bernard H.A. Chuang, ${ }^{1}$ Jill Danne, ${ }^{4,6}$ Sarah L. Ellis, ${ }^{4,6}$ \\ Sze Woei Ng, ${ }^{1}$ Trevor J. Kilpatrick, ${ }^{1,3,5}$ and Tobias D. Merson ${ }^{1,2,5}$ \\ ${ }^{1}$ The Florey Institute of Neuroscience and Mental Health, and ${ }^{2}$ Florey Department of Neuroscience and Mental Health, and ${ }^{3}$ Department of Anatomy and \\ Neuroscience, ${ }^{4}$ Sir Peter MacCallum Department of Oncology, and ${ }^{5}$ Melbourne Neuroscience Institute, The University of Melbourne, Parkville 3010, \\ Victoria, Australia, and 'Peter MacCallum Cancer Centre, East Melbourne 3006, Victoria, Australia
}

Parenchymal oligodendrocyte progenitor cells (pOPCs) are considered the principal cell type responsible for oligodendrogenesis and remyelinaton in demyelinating diseases. Recent studies have demonstrated that neural precursor cells (NPCs) from the adult subventricular zone (SVZ) can also generate new oligodendrocytes after demyelination. However, the relative contribution of NPCs versus pOPCs to remyelination is unknown. We used in vivo genetic fate mapping to assess the behavior of each progenitor type within the corpus callosi (CCs) of mice subjected to cuprizone-induced demyelination. Nestin-CreER ${ }^{T 2}$ and Pdgfra-CreER ${ }^{T 2}$ transgenic mice were crossed with fluorescent Cre reporter strains to map the fate of NPCs and pOPCs respectively. In cuprizone-challenged mice, substantial numbers of NPCs migrated into the demyelinated CC and contributed to oligodendrogenesis. This capacity was most prominent in rostral regions adjacent to the SVZ where NPC-derived oligodendrocytes significantly outnumbered those generated from pOPCs. Sixty-two percent of all nodes of Ranvier in this region were flanked by at least one paranode generated from an NPC-derived oligodendrocyte. Remarkably, g-ratios (ratio of the axon diameter to the diameter of the axon plus myelin sheath) of myelinated axons in regions subject to significant NPC-derived remyelination were equivalent to those of unchallenged controls, and immunoelectron microscopy revealed that NPC-derived myelin was significantly thicker than that generated by pOPCs, regardless of axonal caliber. We also demonstrate that a reduced efficiency of remyelination in the caudal CC was associated with long-term impairment in the maturation of oligodendrogenic NPCs but only transient delay in pOPC differentiation. Collectively, our data define a major distinct role for NPCs in remyelination, identifying them as a key target for enhancing myelin repair in demyelinating diseases.

Key words: demyelination; multiple sclerosis; myelin; neural precursor cells; oligodendrocyte progenitor cells; remyelination

\section{Introduction}

The ensheathment of axons with myelin membranes by oligodendrocytes is critical for the normal function of many neurons in the CNS. Oligodendrocytes facilitate saltatory conduction and provide metabolic and trophic support to the axons they en-

Received Aug. 12, 2013; revised Sept. 4, 2014; accepted Sept. 10, 2014.

Author contributions: T.J.K. and T.D.M. designed research; Y.L.X.,P.T.R., B.H.A.C., J.D.,S.L.E., S.W.N., and T.D.M. performed research; J.A.S.S. contributed unpublished reagents/analytic tools; Y.L.X. and T.D.M. analyzed data; Y.L.X., T.J.K., and T.D.M. wrote the paper.

This work was supported by a Strategic Research Australian Postgraduate Award (Stem Cells Australia; Y.L.X.), a National Health and Medical Research Council of Australia/Multiple Sclerosis Research Australia Betty Cuthbert Fellowship (T.D.M.), and a Neuroscience Institute Fellowship (T.D.M.); and by Stem Cells Australia-the Australian Research Council Special Research Initiative in Stem Cell Science (T.D.M. and T.J.K.). Charity Works for MS and the Victorian Operational Infrastructure Support Program provided additional support. We thank Professor William Richardson (University College London, London, UK), Professor Ryoichiro Kageyama (University of Kyoto, Kyoto, Japan), and Professor Frank Costantini (Columbia University Medical Center, New York, NY) for generously providing the Pdgfra-CreER ${ }^{T 2}$, Nestin-CreER ${ }^{T 2}$ line 5-1, and Rosa26-eYFP transgenic mouse lines, respectively.

The authors declare no competing financial interests.

Correspondence should be addressed to Tobias D. Merson, The Florey Institute of Neuroscience and Mental Health, Parkville 3010, VIC, Australia. E-mail: tmerson@unimelb.edu.au.

DOI:10.1523/JNEUROSCI.3491-13.2014

Copyright $\odot 2014$ the authors $\quad 0270-6474 / 14 / 3414128-19 \$ 15.00 / 0$ sheath (Nave, 2010; Lee et al., 2012; Oluich et al., 2012). The degenerative loss of myelin, known as demyelination, which occurs as a consequence of oligodendrocyte death in diseases such as multiple sclerosis (MS), impairs axonal function and renders neurons vulnerable to permanent injury (Dutta and Trapp, 2011). Restoration of axonal function and rescue from irreversible damage can be mediated via remyelination of denuded axons through the de novo synthesis of myelin from newly generated oligodendrocytes (Irvine and Blakemore, 2008).

Genetic fate-mapping studies have demonstrated that parenchymal oligodendrocyte progenitor cells (pOPCs), defined by the expression of PDGFR $\alpha$ and NG2 proteoglycan, generate new oligodendrocytes that contribute to remyelination following demyelinating insults (Tripathi et al., 2010; Zawadzka et al., 2010). Recent studies suggest that a distinct population of neural precursor cells (NPCs) resident within the adult subventricular zone (SVZ) of the lateral ventricles could represent an alternate source of progenitors for remyelination (Huang et al., 2011). In the quiescent state, SVZ-derived NPCs are responsible for the generation of neuroblasts that migrate to the olfactory bulbs, where they differentiate into inhibitory interneurons (Lois and Alvarez- 
Buylla, 1994; Gage, 2000). In contrast, upregulated production of oligodendrocytes from NPCs has been reported in experimental models where focal demyelination occurs adjacent to the SVZ and in postmortem tissue obtained from MS patients (NaitOumesmar et al., 1999; Petratos et al., 2004; Menn et al., 2006). Thus, NPCs could provide an alternative endogenous source of myelinating oligodendrocytes (Huang et al., 2011).

Although previous studies have demonstrated that SVZderived NPCs exhibit the capacity to migrate into demyelinating lesions and differentiate into oligodendrocytes, the extent to which NPCs, as opposed to pOPCs, contribute to remyelination remains uncertain. We have performed independent CreER-loxP fate mapping of NPCs and pOPCs to directly assess the relative contribution of these distinct precursor populations to oligodendrogenesis and remyelination after cuprizone-induced demyelination of the corpus callosum (CC). We provide definitive evidence that demyelination induces the migration of large numbers of NPCs into the CC, where they adopt a predominantly oligodendroglial fate and contribute substantially to remyelination. NPC-derived oligodendrocytes are the principal source of new oligodendrocytes in regions of the rostral CC adjacent to the SVZ, and they become more broadly distributed throughout the remyelinated CC in a complementary pattern to that of pOPCderived oligodendrocytes, thereby restoring normal oligodendrocyte density throughout the parenchyma of the CC. We also identify a reduced efficiency of NPC-mediated remyelination in the caudal CC due to a long-term impairment in the maturation of oligodendrogenic NPCs in this segment. Finally, we reveal that g-ratios (ratio of the axon diameter to the diameter of the axon plus myelin sheath) of axons myelinated by NPC-derived oligodendrocytes are significantly lower than those myelinated by pOPCs, regardless of axon caliber. Collectively, our data demonstrate that NPCs are a major source of morphologically distinct oligodendrocytes that participate in remyelination of the corpus callosum, a process that could be targeted to improve myelin repair.

\section{Materials and Methods}

Animal cohorts. Nestin-CreER ${ }^{T 2}$ line 5-1 transgenic mice (Imayoshi et al., 2006) expressing a CreER ${ }^{\mathrm{T} 2}$ fusion protein under the control of the rat nestin gene promoter and second intronic enhancer were crossed to one of two reporter mouse lines, Rosa26-eYFP (Srinivas et al., 2001) and $m T m G$ (Muzumdar et al., 2007), to produce Nestin-CreER ${ }^{T 2}$ line 5-1: Rosa26-eYFP transgenic mice (denoted Nestin:YFP) and Nestin-CreER ${ }^{T 2}$ line 5-1:mTmG transgenic mice (denoted Nestin: $m T m G$ ), respectively. Pdgfra-CreER ${ }^{T 2}$ :Rosa26-eYFP mice (denoted Pdgfra:YFP) have been previously described (Rivers et al., 2008), and we also generated Pdgfra$C r e E R^{T 2}: m T m G$ transgenic mice (denoted Pdgfra:mTmG). All experimental mice were maintained on a pure C57BL/6 background. Both males and females were used in the study. Animal experiments were performed in accordance with the National Health and Medical Research Council guidelines and were approved by the animal ethics committee of The Florey Institute of Neuroscience and Mental Health (Parkville, VIC, Australia).

Tamoxifen induction. Recombination was induced by oral gavage of tamoxifen (TAM; catalog \#T5648, Sigma) delivered at a dose of 0.3 $\mathrm{g} / \mathrm{kg} / \mathrm{d}$ for 4 consecutive days. Tamoxifen was prepared at $40 \mathrm{mg} / \mathrm{ml}$ in corn oil (catalog \#C8267, Sigma). Vehicle controls received corn oil without tamoxifen.

Induction of demyelination using cuprizone. Cuprizone administration commenced $7 \mathrm{~d}$ after the final tamoxifen or oil gavage. Animals were housed under standard laboratory conditions with food and water ad libitum. Mice were fed with $0.2 \%$ cuprizone (w/w; bis-cyclohexanoneoxaldihydrazone; catalog \#C9012, Sigma) in dry powdered chow. Transgenic and wild-type C57BL/6 mice were assessed after ingesting cuprizone diet for a period of 2, 2.5, 3, 3.5, or 4 consecutive weeks $(n=$ 4-6/group). Additional cohorts were administered cuprizone for 6 weeks then returned to a normal diet for a period of either 6 or 14 weeks of recovery; control mice were fed normal powdered food $(n=$ 4-6/group).

Tissue processing and immunohistochemistry. Mice were deeply anesthetized with $100 \mathrm{mg} / \mathrm{kg}$ sodium pentobarbitone and then perfused transcardially with PBS, followed by $4 \%$ PFA/PBS. Brains were removed and post-fixed in $4 \%$ PFA/PBS for $2 \mathrm{~h}$ on ice, transferred to PBS overnight, cryopreserved in $20 \%$ sucrose/PBS overnight, followed by embedding in Tissue-Tek OCT compound (Sakura FineTek). The brains were stored at $-80^{\circ} \mathrm{C}$ until sectioned. Sections of $10 \mu \mathrm{m}$ thickness were obtained in the coronal and sagittal planes using a Leica cryostat, collected onto Superfrost Plus slides (Menzel Glaser), and air dried for $1 \mathrm{~h}$ before storing at $-80^{\circ} \mathrm{C}$ until stained. Cryosections were air dried, then blocked with PBS containing $0.3 \%$ Triton X-100, 10\% normal donkey serum, and 10\% BlokHen (Aves Labs) for $1 \mathrm{~h}$ at room temperature (RT). The sections were then incubated with primary antibodies at RT overnight, followed by $1 \mathrm{~h}$ incubation at RT with secondary antibody. For double or multiple labeling, some primary antibodies were incubated simultaneously [Nestin/yellow fluorescent protein (YFP); CC1/PDGFR $\alpha$ /YFP; Sox10/GFAP/ YFP; Sox10/doublecortin (Dcx)/YFP, Olig1/Sox10/PDGFR $\alpha / Y F P$, Gpr17/ PDGFR $\alpha / \mathrm{CC} 1 / \mathrm{YFP}$, and CNPase/PDGFR $\alpha / \mathrm{CC} 1 / \mathrm{YFP}$ for cell fate analysis; CNPase/SMI312/membrane-targeted green fluorescent protein (mGFP), MBP/SMI312/mGFP, CNPase/voltage-gated sodium channel type 1.6 $\left(\mathrm{Na}_{\mathrm{v}} 1.6\right) / \mathrm{mGFP}$, and Caspr/ $\mathrm{Na}_{\mathrm{v}} 1.6 / \mathrm{mGFP}$ for analysis of myelin and node integrity]. The following primary antibodies were used: mouse anti-Nestin (1:100; Millipore), mouse anti-APC/CC1 (1:100; Calbiochem), goat anti-PDGFR $\alpha$ (1:150; R\&D Systems), mouse anti-GFAP (1:200; Millipore), goat anti-Dcx (1:100; Santa Cruz Biotechnology), rabbit anti-Gpr17 (1:400; Cayman Chemical), rabbit anti-Sox10 (1:500; Millipore), mouse anti-Olig1 (1:200; Millipore Bioscience Research Reagents), mouse anti-SMI312 (1:1000; Convance), rabbit anti-CNPase (1:200; Cell Signaling Technology), rabbit anti-MBP (1:200; Calbiochem), rabbit anti-Na 1.6 (1:200; Alomone Labs), mouse anti-Caspr (1: 100; NeuroMab), and chicken anti-GFP (1:2000; Aves Labs). Secondary antibodies raised in donkey and conjugated to FITC, TRITC, 7-amino4-methylcoumarin-3-acetic acid (AMCA), or Alexa Fluor-647 were purchased from Jackson ImmunoResearch or Invitrogen and used at 1:200 dilution. Sections incubated with biotinylated secondary antibody were rinsed and further incubated with streptavidin-Brilliant Violet 421 (1: 200; BioLegend) for $30 \mathrm{~min}$. Slides stained without the fluorophore AMCA or Brilliant Violet 421 were also counterstained with Hoechst 33342 ( $1 \mu \mathrm{g} / \mathrm{ml}$; Invitrogen). To visualize myelin, slides were stained with either FluoroMyelin Red (1:300; Life Technologies) for 1 h, or BlackGold II (1:10; Biosensis) according to the manufacturer's instructions. Sections were coverslipped with Mowiol mounting medium or Vectashield mounting medium (Vector Laboratories), and subjected to fluorescence and confocal microscopic analysis.

To identify pOPC-derived oligodendrocytes generated during the fourth week of cuprizone challenge, $P d g f r a: Y F P$ mice were administered 5 '-ethynyl-2'-deoxyuridine (EdU; Life Technologies) in their drinking water $(0.2 \mathrm{mg} / \mathrm{ml})$ during the fourth week of cuprizone challenge. The water was changed every alternate day. To assess EdU incorporation in oligodendrocytes, sections were first processed for YFP and CC1 immunohistochemistry as above, followed by EdU detection using the Alexa Fluor-647 Click-iT EdU Cell Proliferation Assay kit (Life Technologies) according to the manufacturer's instructions.

Confocal microscopy and image analysis. Stained coronal and parasagittal sections were imaged by laser-scanning confocal microscopy (FV1000, Olympus; or LSM510-META, Zeiss), which was used to detect up to four fluorophores by laser excitation at 405, 488, 561, and $633 \mathrm{~nm}$ wavelengths. Sections were typically captured at a magnification of $20-$ $60 \times$. Tile scanning was performed for the analysis of regional distribution in the entire CC and confocal images were then imported into Photoshop (Adobe Systems) or ImageJ software (NIH) for quantification of cellular density and quantitative analysis of myelin formation and node integrity in the CC. From three to six coronal sections were examined for each animal at each of the rostral, middle, and caudal segments 
of the CC, between levels +1.10 and $-1.94 \mathrm{~mm}$ relative to bregma. Parasagittal sections were collected between 0.84 and $2.40 \mathrm{~mm}$ lateral to the midline (Paxinos and Franklin, 2008). To assess the regional distribution of cells in the Nestin:YFP and Pdgfra:YFP mice following cuprizone-induced demyelination, cell density was quantified in the CC relative to the distance from the dorsolateral corner of SVZ. The frequency distribution of $\mathrm{CCl}^{+} \mathrm{YFP}^{+}$cells in the Pdgfra:YFP mice was calculated by dividing the number of $\mathrm{CC}^{+}{ }^{+} \mathrm{YFP}^{+}$cells within each mediolateral region by the total number of $\mathrm{CC}^{+}{ }^{+} \mathrm{YFP}^{+}$cells within that specific segment of the CC. We used this approach because recombination within parenchymal PDGFR $\alpha^{+}$pOPCs was not $100 \%$ efficient and varied somewhat between animals. To obtain the density of mGFPexpressing myelin rings in the rostral and caudal CC of Nestin:mTmG mice, the number of myelin rings was divided by the area analyzed. The density of paranode pairs double positive, single positive, or negative for mGFP was obtained by dividing the number of pairs by the area analyzed. For quantification of myelin intensity, images from the sections stained with Black-Gold II (or FluoroMyelin Red; data not shown) were converted to grayscale images in Adobe Photoshop, and automated measurements of myelin intensity were taken using the measurement function of ImageJ to record the mean gray value within the regions of interest. Quantitative data are reported as mean \pm SEM. All cell counts and analyses were performed blind to the experimental treatment.

Transmission electron microscopy. Wild-type C57BL/6 mice $(n=3-4 /$ group) were perfused with PBS, followed by $4 \%$ PFA/ $0.2 \%$ glutaraldehyde/PBS. The brains were removed and placed in a stainless steel mouse brain matrix for the collection of 1-mm-thick coronal slices. These tissue slices were post-fixed immediately in modified Karnovsky fixative $(2.5 \%$ glutaraldehyde, $4 \%$ PFA, $0.1 \mathrm{~m}$ sodium cacodylate, $\mathrm{pH} 7.3)$ at $4^{\circ} \mathrm{C}$ overnight. Then tissues were rinsed three times in $0.1 \mathrm{M}$ sodium cacodylate buffer, $\mathrm{pH} 7.3$, and stored in the same buffer at $4^{\circ} \mathrm{C}$ until trimming. The $\mathrm{CC}$ was identified in the tissue blocks under a dissecting microscope, and segments of the CC were trimmed to regions of interest in the midline and the region adjacent to the SVZ for each of the rostral and caudal coronal slices. These blocks were then post-fixed in $1 \%$ osmium tetroxide, dehydrated through a graded series of alcohols followed by two changes of acetone and embedded in the low-viscosity resin of Spurr (1969). Semi-thin $(1 \mu \mathrm{m})$ sections were cut in the sagittal orientation with a Leica EM UC7 ultramicrotome and stained with toluidine blue. The CC in the semi-thin sections was identified, and ultrathin $(\approx 90 \mathrm{~nm})$ sections of this region of interest were collected and contrasted with lead citrate and aqueous uranyl acetate and mounted on copper mesh grids. Sections were examined in a JEOL 1011 transmission electron microscope, and images were captured with a MegaView III CCD cooled camera operated with iTEM AnalySIS software (Olympus Soft Imaging Systems $\mathrm{GmbH}$ ). Images were imported into ImageJ to analyze the density of myelinated and unmyelinated axons (10 images per animal, $n=$ 3-4 animals/group). G-ratios (axon diameter/diameter of the axon plus myelin sheath) were calculated using two images per animal at 6 weeks of recovery ( $n=3-4 /$ group).

Immunoelectron microscopy. The protocol for immunolabeling the brain sections, amplification of the fluorescent signal, gold labeling, and subsequent silver enhancement of the gold were performed according to Ellis et al. (2009). Briefly, TAM/cuprizone-challenged Nestin:mTmG and Pdgfra: $m$ Tm $G$ mice at 6 weeks of recovery after cuprizone withdrawal were transcardially perfused with $4 \%$ PFA (EM grade) $/ 0.1 \%$ glutaraldehyde in PBS. The brains were post-fixed in $4 \%$ PFA/ $0.1 \%$ glutaraldehyde in HEPES-buffered saline (HBS) for $1 \mathrm{~h}$ on ice then in 4\% PFA in HBS at $4^{\circ} \mathrm{C}$ overnight. Coronal sections $(150 \mu \mathrm{m}$ thick) were cut with a Vibratome (VT1000P, Leica Microsystems $\mathrm{GmbH}$ ) and stored in $2.3 \mathrm{M}$ sucrose in $0.1 \mathrm{M}$ Sorensen's phosphate buffer, $\mathrm{pH} 7.4$, at $4^{\circ} \mathrm{C}$ until processed. Free-floating sections were permeabilized, and nonspecific binding sites were blocked with HBS plus $10 \%$ bovine serum albumin (BSA) and $0.05 \%$ Triton X-100 (Roche Diagnostics). Optimally titrated chicken anti-GFP antibody (GFP-1020, Aves Labs) was added at a final concentration of $5 \mu \mathrm{g} / \mathrm{ml}$ in a diluent of HBS plus $1 \%$ BSA and $0.005 \%$ Triton $\mathrm{X}-100$, and incubated at $4^{\circ} \mathrm{C}$ overnight. Following washing in PBS plus $0.05 \%$ BSA, sections were incubated with biotinylated goat anti-chicken IgY antibody (Vector Laboratories) at a concentration of $7.5 \mu \mathrm{g} / \mathrm{ml}$ for 30 min. Signal amplification was performed using fluorescein tyramide amplification (PerkinElmer Life Sciences) for $6 \mathrm{~min}$. FITC was labeled with a mouse anti-FITC antibody conjugated to ultra small gold (Aurion) for $2 \mathrm{~h}$, and sections were post-fixed in $2 \% \mathrm{PFA} / 2.5 \%$ glutaraldehyde in $0.1 \mathrm{M}$ cacodylate buffer. Gold was silver enhanced with R-GENT SE-EM (Aurion) for $60 \mathrm{~min}$. Following extensive washing in distilled water, the sections were fixed in $1 \%$ osmium tetroxide, $1.5 \%$ potassium ferrocyanide in distilled water, dehydrated through a graded series of alcohols, rinsed in acetone, and embedded in the resin of Spurr (1969). Before polymerization of the resin, the brain slices were trimmed with a doubleedged razor blade to the areas of interest. Ultrathin sections were cut with a Leica EM UC7 ultramicrotome, and contrasted with lead citrate and aqueous uranyl acetate before mounting on copper grids for TEM. As a negative control, brain sections from TAM/cuprizone Nestin-CreER ${ }^{T 2}$ line 5-1 single transgenic mice, which were devoid of GFP, were labeled following the above protocol. G-ratio analysis of gold-labeled myelin sheaths was performed as described above.

Statistical analyses. All statistical analyses were performed using GraphPad Prism software. Statistical significance was determined using unpaired Student's $t$ test, one-way ANOVA, or two-way ANOVA with Bonferroni's post hoc multiple-comparison tests. Statistical significance was defined as $p<0.05$.

\section{Results}

The NPC lineage in Nestin:YFP mice expresses YFP after tamoxifen administration

To map the fate of NPCs and their progeny in the adult CNS, we crossed Nestin-CreER ${ }^{T 2}$ line 5-1 transgenic mice (Imayoshi et al., 2006) with the Rosa26-eYFP reporter strain (Srinivas et al., 2001) to generate double-heterozygous Nestin:YFP mice (Fig. 1A). In agreement with previous studies (Imayoshi et al., 2008), virtually all nestin-positive NPCs in the SVZ of Nestin:YFP mice expressed YFP $7 \mathrm{~d}$ following tamoxifen gavage, whereas oil-gavaged mice rarely expressed YFP (Fig. 1B). Additionally, in TAM-gavaged Nestin:YFP mice, no $\mathrm{YFP}^{+}$cells in the adult SVZ coexpressed PDGFR $\alpha$, nor did any of the sparse $\mathrm{YFP}^{+}$cells that were occasionally observed within the area of the corpus callosum adjacent to the SVZ. These data indicate that the Nestin-CreER ${ }^{T 2}$ transgene enables specific labeling of NPCs and ependymal cells lining the lateral ventricles but does not label the pOPC lineage (Fig. 1C).

We applied this genetic labeling approach to track the migration of NPCs in mice subsequently challenged with the copper chelator cuprizone, an agent that induces stereotyped demyelination of the CC (Matsushima and Morell, 2001). Starting $7 \mathrm{~d}$ after tamoxifen gavage, Nestin:YFP mice were fed cuprizonesupplemented chow for up to 6 weeks (TAM/cuprizone challenge) followed by 6 or 14 weeks of recovery on normal chow (Fig. 1D). TAM/cuprizone mice assessed 6 weeks after cuprizone withdrawal exhibited robust YFP expression throughout the SVZ (Fig. 1E). Comparable YFP labeling was observed in the SVZ of TAM/control Nestin:YFP mice assessed at an equivalent time after tamoxifen gavage. Oil-gavaged mice on either the cuprizone or control diet for 6 weeks rarely expressed YFP in the SVZ when assessed after an additional 6 weeks on normal chow (Fig. 1E). These data confirm the utility of Nestin:YFP mice to specifically and permanently label adult NPCs and their progeny for longterm assessment of cell fate in the cuprizone model of CNS demyelination.

\section{Substantial numbers of NPCs are recruited into the demyelinated CC}

Previous studies have established that demyelination peaks after 4 to 5 weeks of a 6 week cuprizone challenge and that remyelination is largely complete within an additional 6 weeks of recovery on a normal diet (Morell et al., 1998; Matsushima and Morell, 
A

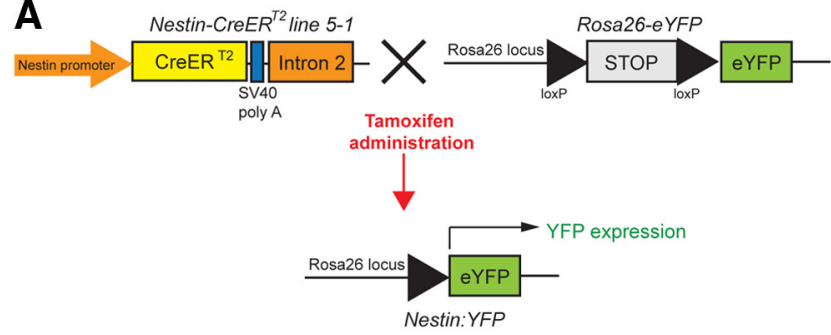

B
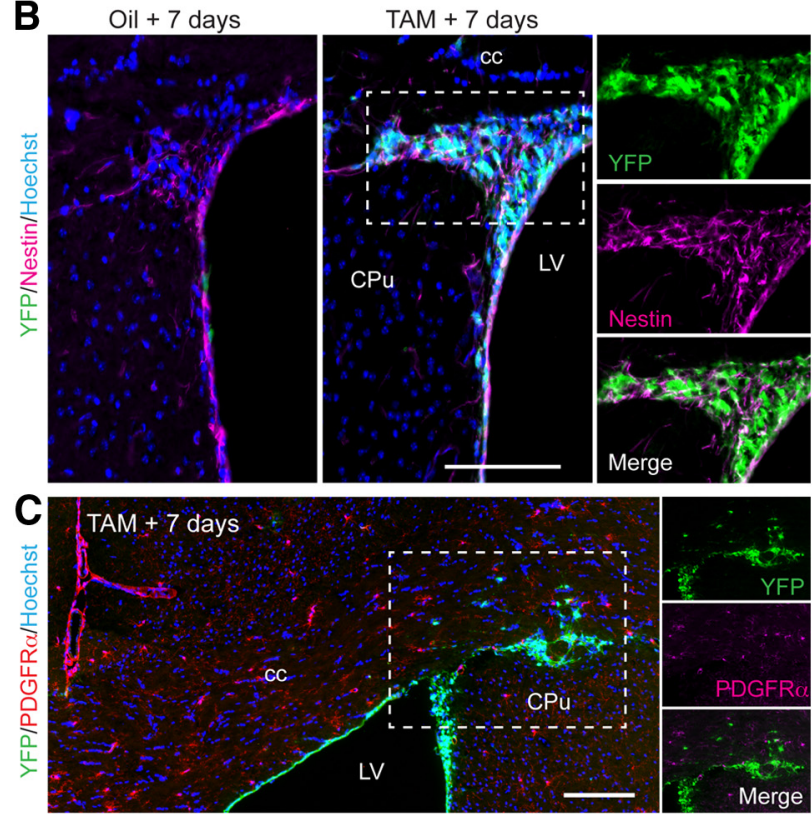

D

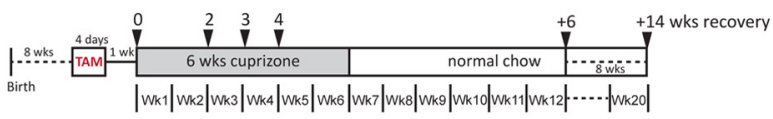

$\mathbf{E}$
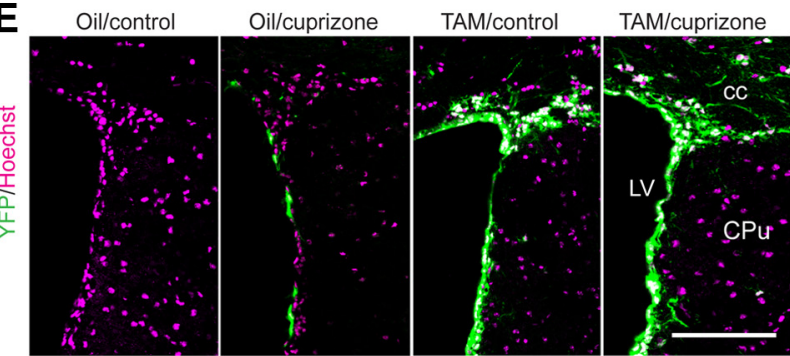

AM/control TAM/cuprizone

Figure 1. Genetic labeling of NPCS in the adult SVZ. A, Schematic representation of the transgenic alleles in Nestin:YFP mice showing the tamoxifen-responsive recombination of the Rosa26-eYFP allele to induce YFP expression. $\boldsymbol{B}$, Coronal sections of the SVZ were immunolabeled with antibodies against YFP and Nestin $7 \mathrm{~d}$ after oil or tamoxifen administration before cuprizone challenge. Hoechst 33342 was used as a nuclear counterstain. C, Coronal section of the rostral CC immunolabeled with antibodies against YFP and PDGFR $\alpha 7 \mathrm{~d}$ after tamoxifen administration, and before cuprizone challenge, demonstrating the absence of colocalization of YFP and PDGFR $\alpha$. D, Experimental design indicating time points for tamoxifen/oil gavage, cuprizone challenge, and tissue collection (black arrowheads). $\boldsymbol{E}$, Coronal sections of the SVZ immunolabeled with an antibody against YFP and counterstained with Hoechst 33342 at 6 weeks of recovery after cuprizone withdrawal. No YFP expression was observed in oil-treated control mice. A low level of YFP expression was observed in oil-treated mice following cuprizone challenge, indicative of minimal tamoxifen-independent Cre-mediated recombination. Tamoxifen treatment led to YFP expression in both control and cuprizone-challenged mice. Cpu, Caudate-putamen; LV, lateral ventricle. Scale bars, $150 \mu \mathrm{m}$.

2001; Gudi et al., 2009). Consistent with these reports, histological analysis of brain sections from cuprizone-challenged wildtype mice stained with Black-Gold II revealed a progressive decline in myelin staining in rostral and caudal segments of the
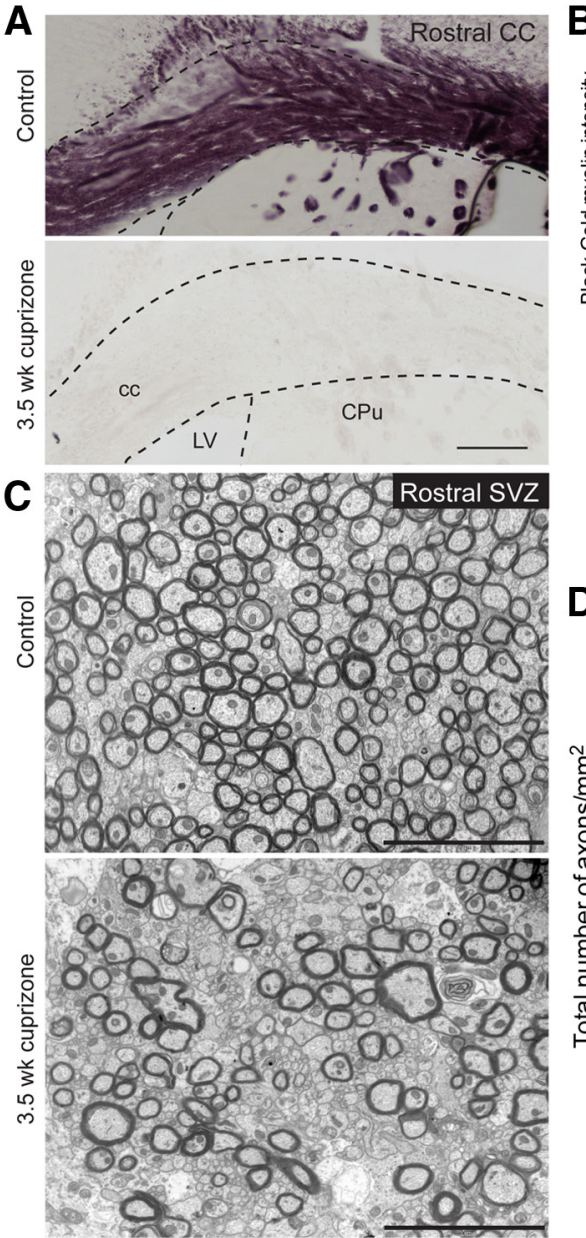

B
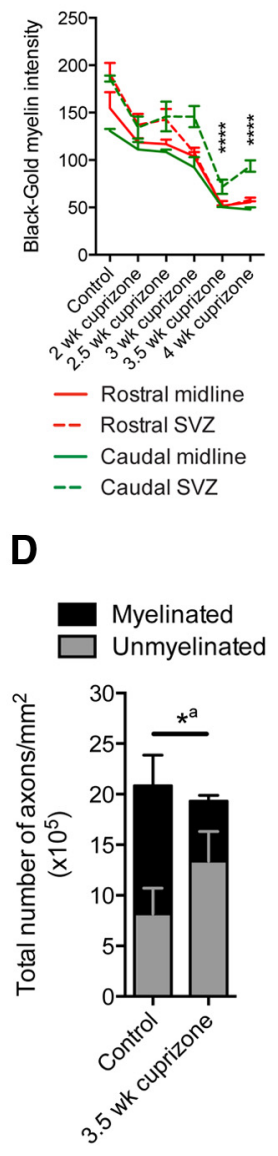

Figure 2. Cuprizone-induced demyelination in the entire CC. $\boldsymbol{A}$, Representative images of Black-Gold II-stained coronal sections of rostral CC of unchallenged and 3.5 week cuprizonechallenged wild-type mice. Dashed lines indicate borders of the lateral ventricles and CC. $\boldsymbol{B}$, Quantification of the mean Black-Gold II myelin intensity in the midline of the rostral and caudal $C C$, and the regions adjacent to the SVZ at the indicated time points. $C$, Representative electron micrographs of the region of the CC adjacent to the SVZ in unchallenged and 3.5 week cuprizone-challenged wild-type mice. $\boldsymbol{D}$, Stacked histograms displaying the total number of myelinated (black) and unmyelinated (gray) axons in control versus cuprizone-exposed mice $\left({ }^{* a} p<0.05\right.$, unpaired two-tailed Student's $t$ test for myelinated axons). Cpu, Caudate-putamen: LV, lateral ventricle. Scale bars: $\boldsymbol{A}, 250 \mu \mathrm{m} ; \boldsymbol{C}, 5 \mu \mathrm{m}$. Mean \pm SEM values are shown.

CC, both at the midline and in the region adjacent to the SVZ (Fig. 2A,B). Black-Gold II intensity was markedly reduced by 3.5 weeks of cuprizone challenge, and similar results were obtained using the histochemical stain FluoroMyelin Red (data not shown). The gradual decrease in myelin intensity was also similarly detected in Nestin:YFP mice at 4 weeks of cuprizone challenge (data not shown). To further validate the loss of myelin in the CC adjacent to the SVZ, we performed an ultrastructural analysis of the rostral segment of the corpus callosum in the region adjacent to the SVZ. Compared with unchallenged controls, mice challenged with cuprizone for 3.5 weeks exhibited a $56.1 \pm 15.0 \%$ reduction in the density of myelinated axons in this rostral segment (Fig. 2C,D, stacked histogram). These data demonstrate that by 3.5 weeks of cuprizone challenge, there is already significant demyelination throughout the corpus callosum, including the rostral segment adjacent to the SVZ.

To establish the extent to which NPCs contribute to oligodendrogenesis during remyelination of the CC, TAM-gavaged Nestin:YFP mice were challenged with cuprizone for 6 weeks 
then were assessed an additional 6 weeks after cuprizone withdrawal (Fig. 3A). Compared with TAM/control Nestin:YFP mice, TAM/cuprizone mice had a 23-fold increase in the density of $\mathrm{YFP}^{+}$cells in the $\mathrm{CC}$, which is indicative of substantial recruitment of NPCs to this region (Fig. 3B). Oil/control and Oil/cuprizone mice exhibited negligible tamoxifen-independent recombination, resulting in rare $\mathrm{YFP}^{+}$cells in the $\mathrm{CC}$ and germinal niches (Fig. 3B).

We next assessed the lineage identity of $\mathrm{YFP}^{+}$cells in the CC of TAM/cuprizone Nestin:YFP mice at the 6 week recovery time point (Fig. 3C). On average, $51.7 \pm$ $4.3 \%$ of $\mathrm{YFP}^{+}$cells coexpressed the oligodendroglial marker Sox10, but not GFAP, whereas $34.8 \pm 2.4 \%$ of $\mathrm{YFP}^{+}$cells were $\mathrm{GFAP}^{+}$. Fewer than $3 \%$ of YFP ${ }^{+}$cells coexpressed Sox10 and GFAP (Fig. 3D). On the other hand, only $9 \%$ of $\mathrm{YFP}^{+}$cells expressed Dcx, none of which coexpressed Sox10. Importantly, the percentage of $\mathrm{YFP}^{+}$cells that contributed to each of these lineages did not differ according to their position in the rostrocaudal axis of the CC (Fig. 3D).

\section{The density of NPC-derived oligodendroglia and their differentiation state vary along the rostrocaudal axis of the remyelinating $\mathrm{CC}$}

NPC-derived oligodendroglia, defined as Sox $10^{+} \mathrm{GFAP}^{-} \mathrm{YFP}^{+}$cells, and hereafter denoted as Sox $10^{+} \mathrm{YFP}^{+}$cells, were distributed in a distinctly nonuniform pattern along the rostrocaudal axis of the $\mathrm{CC}$ of TAM/cuprizone Nestin:YFP mice examined 6 weeks after cuprizone withdrawal. Sox $10^{+} \mathrm{YFP}^{+}$cell density was highest in the most rostral and caudal segments of the $\mathrm{CC}$, and lowest in middle segments between bregma positions 0.0 and -1.0 (Fig. $4 A$, dashed blue line). To establish whether this $\mathrm{U}$-shaped distribution also defined the segmental densities of oligodendroglial subpopulations, we labeled sections with antibodies against YFP, PDGFR $\alpha$, and CC1 to identify NPC-derived oligodendrocyte progenitor cells and NPC-derived mature oligodendrocytes, respectively (Fig. $4 B$ ). With each successive caudal increment beyond bregma position -1.0, NPC-derived mature oligodendrocytes $\left(\mathrm{CC}^{+}{ }^{+} \mathrm{YFP}^{+}\right.$cells $)$accounted for progressively lower proportions of the total Sox $10^{+} \mathrm{YFP}^{+}$cell population (Fig. 4A). In contrast, $\mathrm{CC}^{+}{ }^{+} \mathrm{YFP}^{+}$cells in rostral and middle segments represented most of the Sox $10^{+} \mathrm{YFP}^{+}$population.

The incomplete maturation of NPC-derived oligodendroglia in the caudal segment was confirmed by profiling the expression of immature oligodendroglial markers. Compared with the rostral CC, the caudal segment contained a higher density of immature oligodendroglia identified as $\mathrm{CC}^{-}{ }^{-} \mathrm{CNPase}^{+} \mathrm{YFP}^{+}$cells (Fig. $4 C$, arrowhead, $F$, stacked histograms). The difference was also evident when expressing the abundance of $\mathrm{CCl}^{-} \mathrm{CNPase}^{+} \mathrm{YFP}^{+}$cells as a percentage of Sox $10^{+} \mathrm{YFP}^{+}$cell density (caudal, $29.8 \pm 5.4 \%$; rostral, $4.1 \pm 0.9 \%$; two-tailed $t$ test, $p<0.01$ ). Consistent with these data, the caudal CC contained a higher density of Sox $10^{+}$ $\mathrm{YFP}^{+}$cells with nuclear Olig1 protein localization (Fig. 4D, white arrowhead, $F$, stacked histograms), confirming the existence of a pool of NPC-derived premyelinating oligodendroglia (Arnett et al., 2004; Niu et al., 2012). The percentage of Sox $10^{+} \mathrm{YFP}^{+}$cells that exhibited nuclear rather than cytoplasmic Olig1 expression was $49.0 \pm 3.5 \%$ in the caudal CC, but just $5.7 \pm 0.6 \%$ in the rostral CC (two-tailed $t$ test, $p<0.0001$ ). Similar densities of $\operatorname{PDGFR} \alpha^{-}$Gpr $17^{+}$cells and PDGFR $\alpha^{+}$Gpr $17^{+}$cells in rostral and caudal segments of the CC confirmed that NPC-derived $\mathrm{CC}^{-}$oligodendroglia in the caudal CC were stalled at a premyelinating stage (Fig. 4G, stacked histograms). Collectively, these data reveal that within 6 weeks of cuprizone withdrawal, NPCderived oligodendroglia contribute substantially to the regeneration of oligodendrocytes, particularly in the rostral CC. High densities of NPC-derived oligodendroglia at a premyelinating stage were restricted to the caudal CC, suggesting that differentiation of NPC-derived oligodendroglia occurs more slowly and/or with reduced efficiency in the caudal CC compared with the rostral CC.

\section{NPCs exhibit limited migratory potential within the CC}

We next examined the regional distribution of oligodendrocytes along the mediolateral axis of the CC in each of the rostral, middle, and caudal segments. First, we confirmed at the 6 week recovery time point that the total density of $\mathrm{CC}^{+}$oligodendrocytes, regardless of lineage identity, did not differ significantly 
A

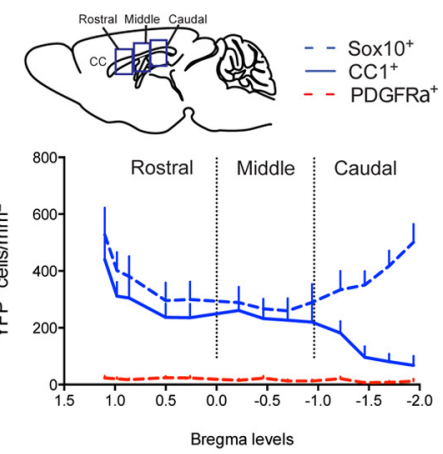

B
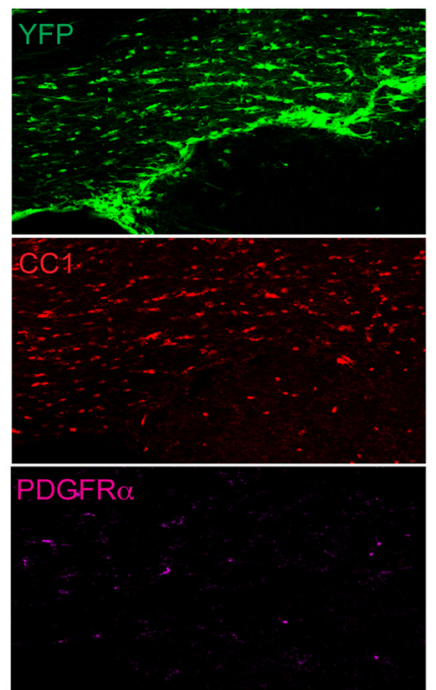

Hoechst
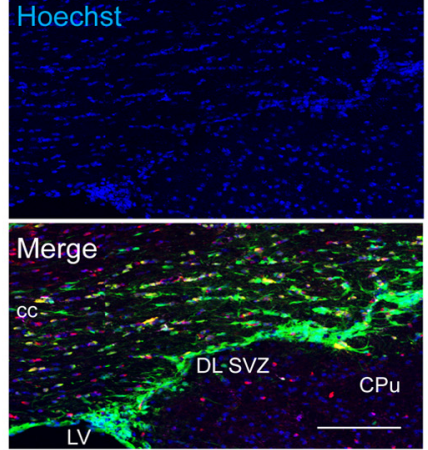

Figure 4. Analysis of the distribution of NPC-derived oligodendroglia within the rostrocaudal axis of the remyelinating CC. $A$, Top, Schematic representation of a sagittal section through an adult mouse brain highlighting the rostral, middle, and caudal segments of the $\mathrm{CC}$ that were analyzed. Bottom, Plot of the distribution of YFP-labeled Sox $10^{+}, \mathrm{CC}^{+}$, or PDGFR $\alpha^{+}$cells along the rostrocaudal axis of $C \mathrm{C}$ of cuprizone-challenged mice. Cell counts were obtained from coronal sections. The data represent the mean density of cells within each segment of CC measured from the midline to lateral extent. B, YFP-labeled CC ${ }^{+}$or PDGFR $\alpha^{+}$ cells in the remyelinating rostral $\mathrm{CC}$ adjacent to the SVZ of the cuprizone-challenged mice. Note that the majority of YFP ${ }^{+}$cells expressed the oligodendrocyte marker $\mathrm{CC} 1$ in this region. $\boldsymbol{C}$, High-magnification confocal image of a YFP-labeled $\mathrm{CC}^{-}{ }^{-} \mathrm{CNPase}{ }^{+}$ cell in the caudal CC adjacent to the SVZ (yellow arrowhead). D, Olig1 was localized in either the nucleus (top, white arrowhead) or the cytosol (bottom, yellow arrowhead) of Sox $10^{+}$YFP $^{+}$cells within the caudal CC adjacent to the SVZ. E, YFP-labeled Gpr17 ${ }^{+}$ or PDGFR $\alpha^{+}$cells within the rostral CC. F, Quantification of NPC-derived oligodendroglia expressing Sox $10 ; \mathrm{CC}^{+}{ }^{+} \mathrm{CNPase}^{+}$or $\mathrm{CC}^{-}$ $\mathrm{CNPase}^{+}$; cytosolic or nuclear Olig1 in the rostral and caudal CC adjacent to the SVZ. Two-way ANOVA was used to compare the mean cell density between rostral and caudal segments of the $\overparen{C}\left({ }^{* *} p<0.01\right)$. G, Quantification of NPC-derived immature OPCs expressing PDGFR $\alpha^{+}$and/or Gpr17 in the same analyzed regions. ns, Notsignificant; $C P u$, caudate-putamen; LV, lateral ventricle; DLSVZ, dorsolateral corner of SVZ. Scale bars: $\boldsymbol{B}, 100 \mu \mathrm{m} ; \boldsymbol{C}, 10 \mu \mathrm{m} ; \boldsymbol{D}, 20 \mu \mathrm{m} ; \boldsymbol{E}, 50 \mu \mathrm{m}$. Mean \pm SEM values are shown.

between TAM/cuprizone and TAM/control Nestin:YFP mice in the rostral, middle, or caudal segments (Fig. 5A). Next, we subdivided the CC into $150 \mu \mathrm{m}$ regions both medial (negative) and lateral (positive) to the dorsolateral corner of the SVZ to assess regional densities of NPC-derived oligodendrocytes (Fig. 5B). In
TAM/cuprizone Nestin:YFP mice, NPCderived oligodendrocytes $\left(\mathrm{CCl}^{+} \mathrm{YFP}^{+}\right.$ cells) represented a high percentage of the total $\left(\mathrm{YFP}^{+}\right.$plus $\left.\mathrm{YFP}^{-}\right) \mathrm{CC}^{+}$cell population within each segment of the CC (rostral, $51.1 \pm 12.7 \%$; middle, $28.5 \pm 7.3 \%$; caudal, $14.7 \pm 1.9 \%)$. The density of NPC-derived oligodendrocytes was highest adjacent to the dorsolateral corner of the SVZ, particularly in the rostral CC, and lower in regions both medial and lateral to the SVZ (Fig. 5B). Remarkably, in the rostral segment adjacent to the SVZ, which we defined as an $1800 \mu \mathrm{m}$ region spanning $900 \mu \mathrm{m}$ both medial and lateral to the dorsolateral corner of the SVZ, NPC-derived oligodendrocytes accounted for $63.8 \pm 7.9 \%$ of the total $\mathrm{CC}^{+}$cell population. In contrast, $\mathrm{YFP}^{-}$oligodendrocytes were distributed at low density adjacent to the SVZ, but at high densities in the midline and lateral regions of the CC (Fig. 5B). These data imply that there exists an inverse relationship between NPC-derived and pOPC-derived oligodendrocytes to account for the relatively consistent total density of oligodendrocytes throughout the remyelinating CC.

To directly assess $\mathrm{POPC}$ fate during the course of remyelination, we generated double-transgenic mice carrying both the Pdgfra-CreER ${ }^{T 2}$ (Rivers et al., 2008) and Rosa26-eYFP alleles (denoted Pdgfra: YFP). Pdgfra:YFP mice were challenged with TAM/cuprizone or TAM/control and assessed 6 weeks after cuprizone withdrawal. We found higher densities of $\mathrm{YFP}^{+}$oligodendrocytes in the medial and lateral regions of the CC of TAM/cuprizone Pdgfra:YFP mice than adjacent to the SVZ, both rostrally and caudally (Fig. 5C$F)$. In contrast, in TAM/control Pdgfra: YFP mice assessed at an equivalent time point, $\mathrm{CC} 1^{+} \mathrm{YFP}^{+}$cells were found to be more evenly distributed between the medial and lateral regions of the CC (Fig. 5E), which is indicative of a basal level of myelin remodeling in the quiescent state, as has recently been reported (Young et al., 2013). Within the medial region of the caudal CC in TAM/cuprizone-challenged Pdgfra:YFP mice, the absolute number of $\mathrm{YFP}^{+}$pOPC-derived oligodendrocytes exceeded those generated in TAM/control mice, whereas the difference between cuprizone and control mice was less marked medially in both the rostral and

middle segments.

Due to variability in the recombination efficiency among pOPCs in the Pdgfra:YFP mice, we normalized the data by first quantifying the total number of $\mathrm{CC}^{+} \mathrm{YFP}^{+}$cells throughout each segment of the CC in both cuprizone and control Pdgfra: 
A

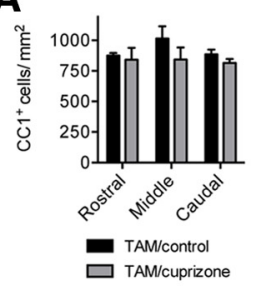

B

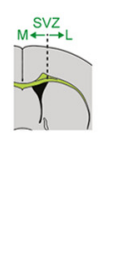

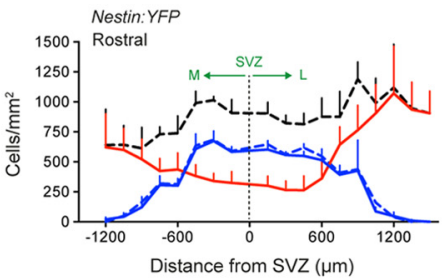
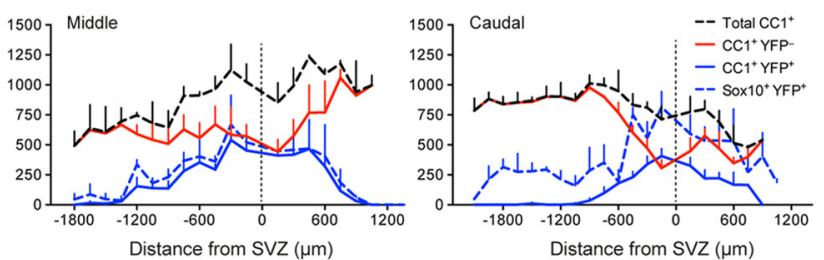

C

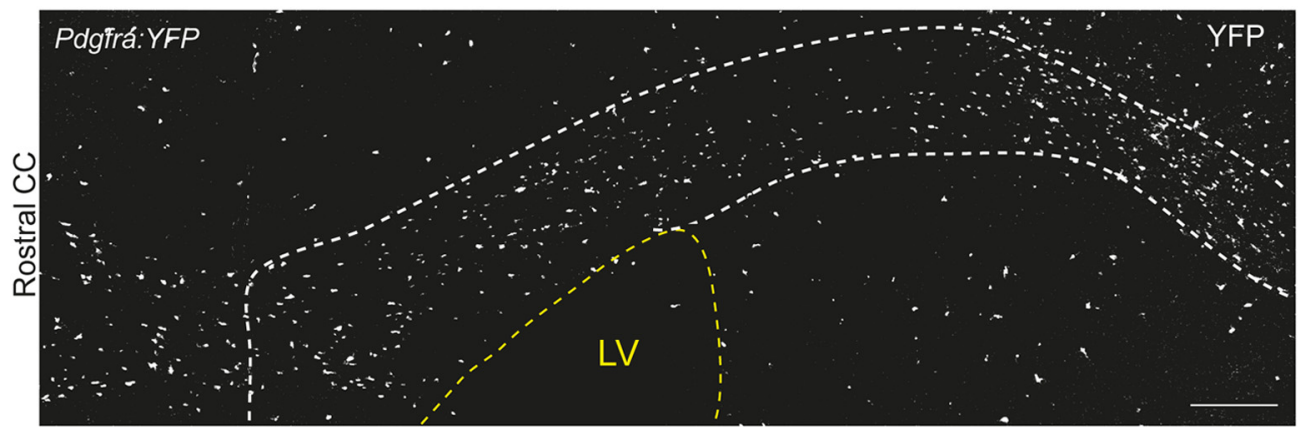

D
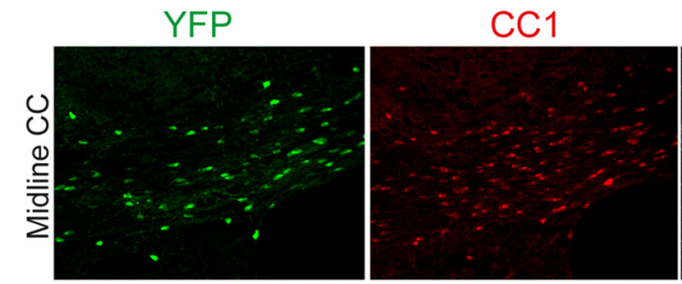

PDGFR $\alpha$

Merge
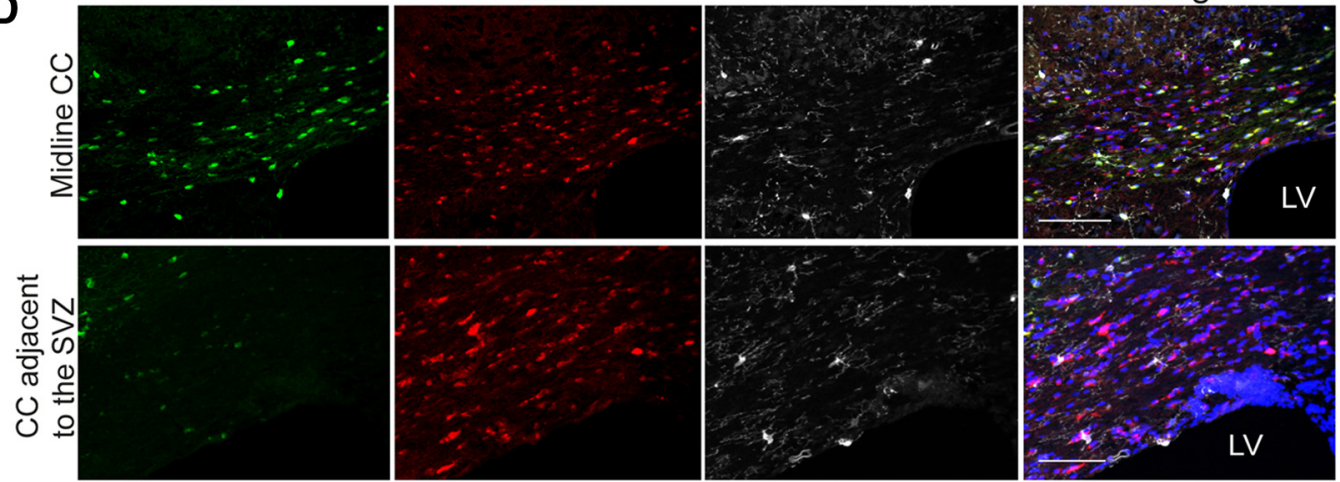

E

Pdgfra:YFP
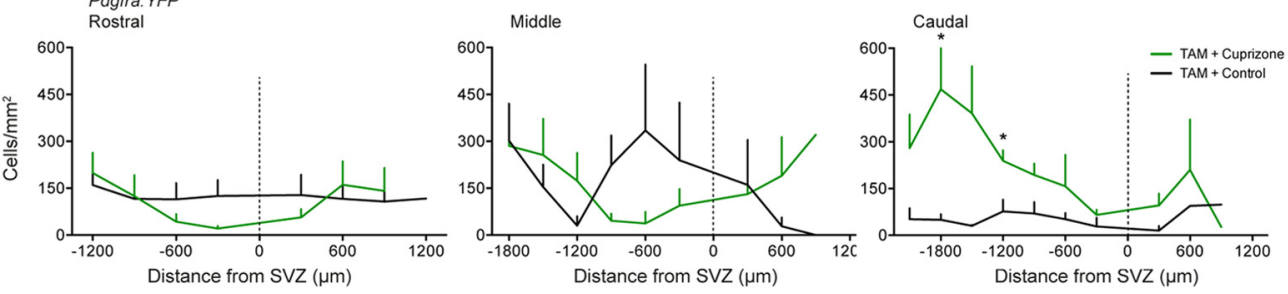

$\mathbf{F}$
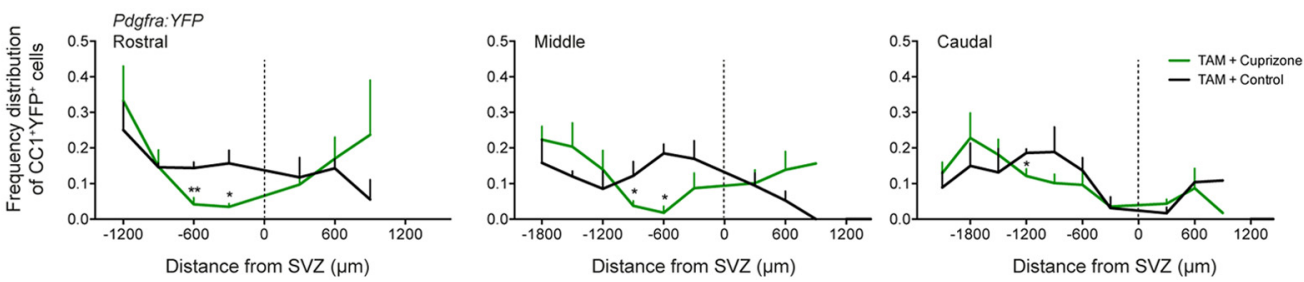

Figure 5. Assessment of the migration potential of NPCs and pOPCs within the remyelinating CC. $A$, Total density of $\mathrm{CC}^{+}{ }^{+}$oligodendrocytes in the rostral, middle, and caudal $C($ of cuprizone-challenged and control mice that were administered tamoxifen. $\boldsymbol{B}$, Left, Schematic representation of medial and lateral regions of the $\mathrm{CC}$ relative to the dorsolateral corner of SVZ used for quantifying cellular distributions along the mediolateral axis. Right, Mediolateral distribution of NPC-derived oligodendrocytes $\left(C C 1^{+}\right.$YFP $^{+}$cells, solid blue line); NPC-derived oligodendroglial lineage cells (Sox $10^{+}$YFP ${ }^{+}$cells, dashed blue line); POPC-derived oligodendrocytes (CC ${ }^{+}$YFP ${ }^{-}$cells, solid red line); and total oligodendrocytes (CC ${ }^{+}$ cells, dashed black line) within the rostral, middle, and caudal segments of the CC of TAM/cuprizone Nestin:YFP mice after 6 weeks of recovery. C, Confocal micrograph of fate-mapped pOPCs in the rostral CC of a TAM/cuprizone-challenged Pdgfra:YFP mouse examined 6 weeks after cuprizone withdrawal. YFP-expressing cells appear as white cell bodies. CC is indicated by the white dashed line. $\boldsymbol{D}$, Higher magnification of the midline CC (top) and the region adjacent to the SVZ (bottom) of a TAM/cuprizone-challenged Pdgfra:YFP mouse at the 6 week recovery time point revealing the cellular expression of YFP, CC1, and/or PDGFR $\alpha$. Nuclei were counterstained with Hoechst 33342. $\boldsymbol{E}$, Mediolateral distribution of p0PC-derived oligodendrocytes $\left(\mathrm{CC}^{+} \mathrm{YFP}^{+}\right.$cells) within the rostral, middle, and caudal segments of the $(C$ of TAM/cuprizone (green) and TAM/control (black) Pdgfra:YFP mice. $\boldsymbol{F}$, Frequency distribution of POPC-derived oligodendrocytes $\left(\mathrm{CC}^{+}{ }^{+} \mathrm{YFP}{ }^{+}\right.$cells) within the rostral, middle, and caudal segments of the CC of TAM/cuprizone (green) and TAM/control (black) Pdgfra:YFP mice. Scale bars: $C, 150 \mu \mathrm{m} ; \boldsymbol{D}$, top, $100 \mu \mathrm{m}$; bottom, $80 \mu \mathrm{m}$. Mean \pm SEM values are shown. 
A

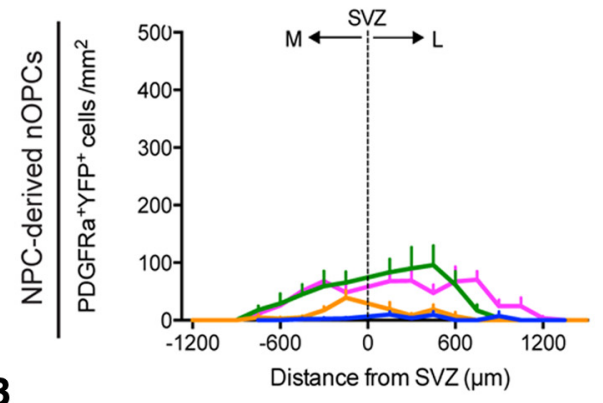

B

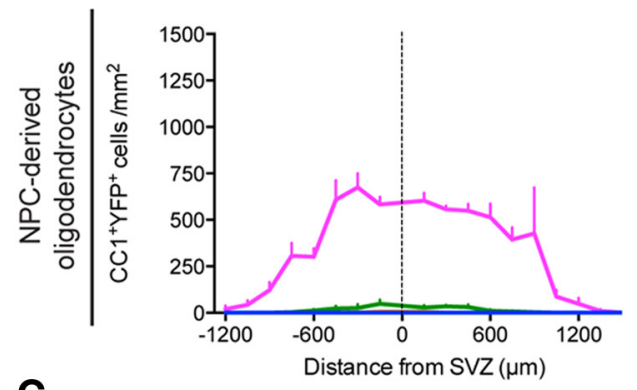

C

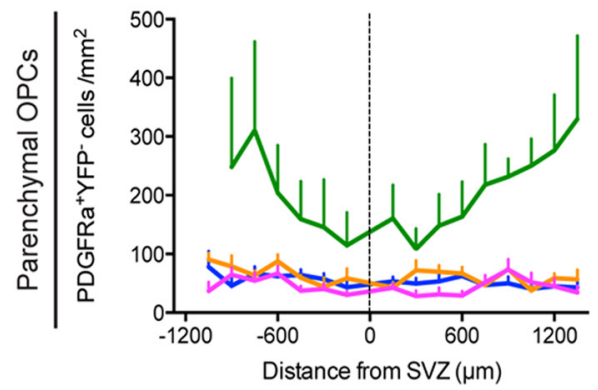

D

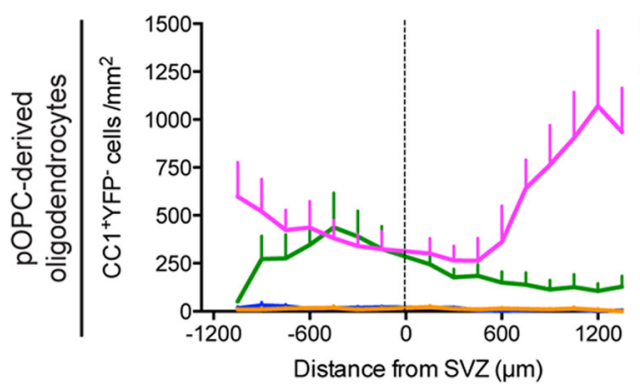

E

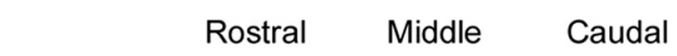

Middle
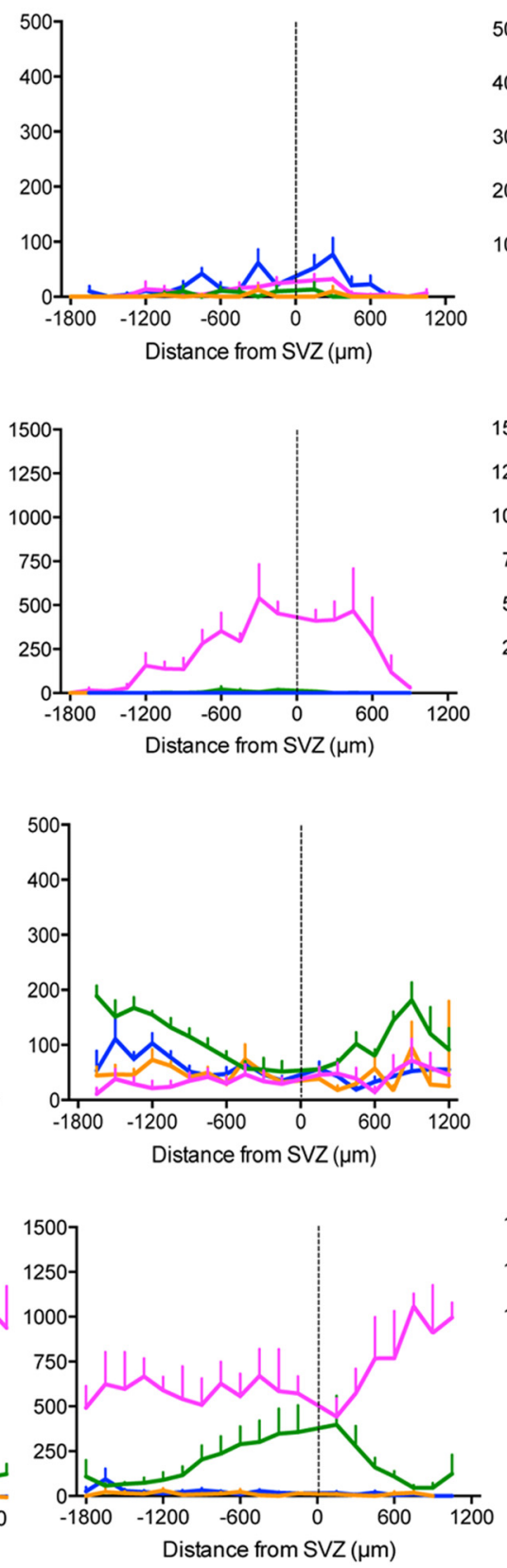

$F$
Caudal
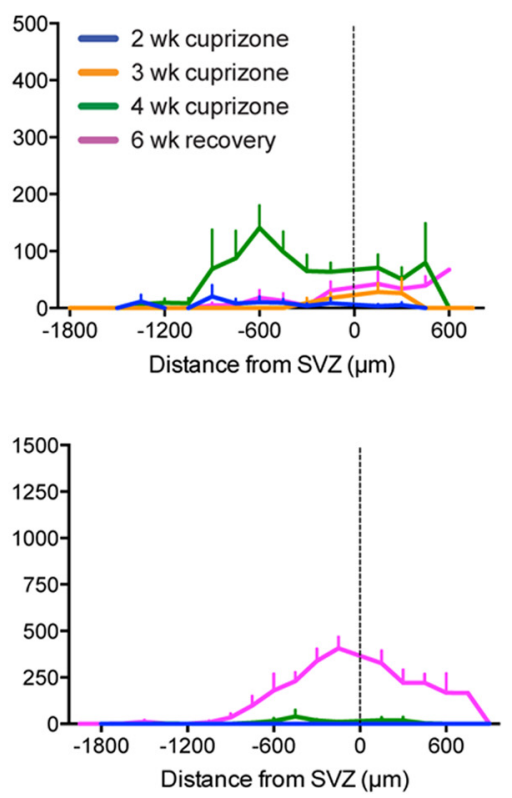
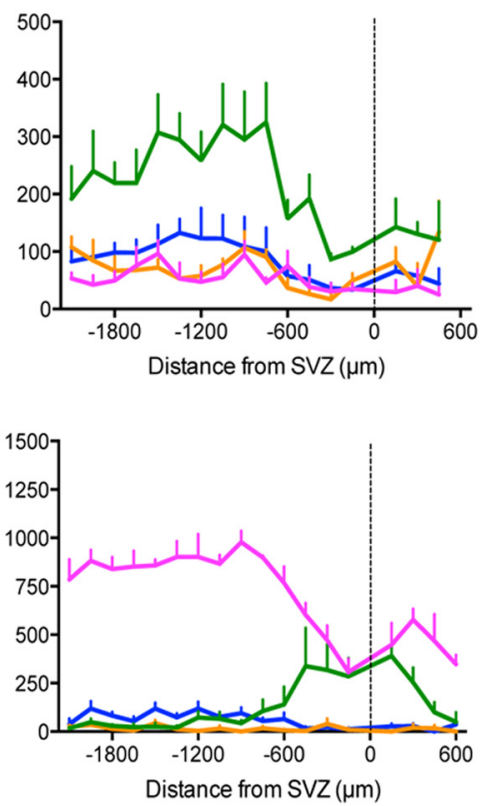

Middle Caudal

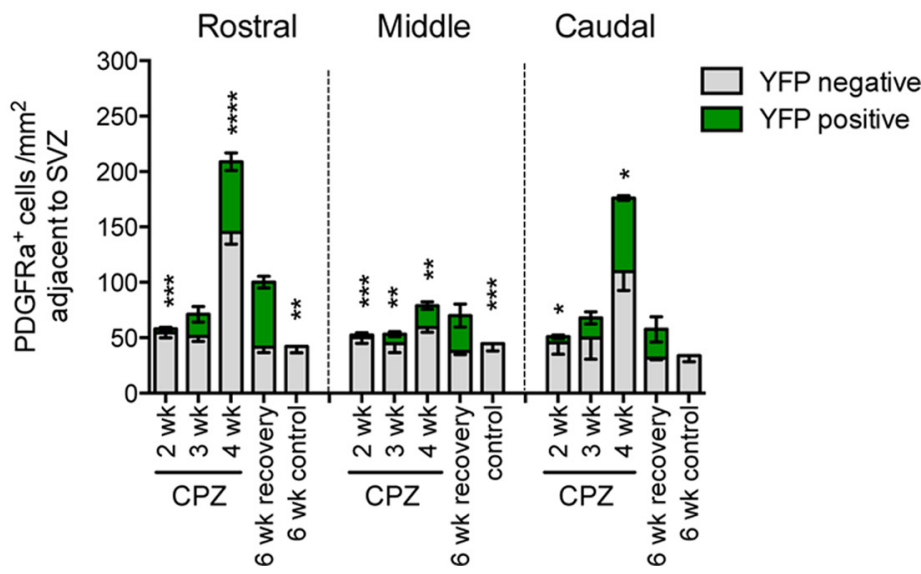


YFP mice. We then determined the proportion of the total number of $\mathrm{CC}^{+} \mathrm{YFP}^{+}$cells that resided in predefined regions along the mediolateral axis of each segment in the rostrocaudal axis to generate frequency distribution plots (Fig. $5 F$ ). Adopting this approach, we found that the proportion of pOPC-derived oligodendrocytes was lower in the region adjacent to the SVZ in the cuprizone-challenged animals compared with controls in both the rostral and middle segments. This was less apparent in the corresponding caudal segment because of the small proportion of $\mathrm{CC}^{+}{ }^{+} \mathrm{YFP}^{+}$cells resident in this region in the control animals. Altogether, these observations demonstrated that subsequent to remyelination, there is, overall, a complementary distribution of NPC-derived and pOPC-derived oligodendrocytes along the mediolateral axis of the CC.

\section{$\mathrm{CC1}^{+}$oligodendrocytes first reappear adjacent to the SVZ and are derived from pre-existing oligodendrocytes}

To investigate the time course of oligodendrocyte regeneration in response to cuprizone-induced demyelination, we examined the brains of TAM/cuprizone-challenged Nestin:YFP mice after 2, 3, and 4 weeks of cuprizone challenge, as well as after 6 weeks of cuprizone withdrawal. NPC-derived OPCs (nOPCs), identified as PDGFR $\alpha^{+} \mathrm{YFP}^{+}$cells, were recruited into the CC at different time points within each rostrocaudal segment of the CC. The earliest population of nOPCs was identified in the middle segment after 2 weeks of cuprizone challenge, which was also the time point of peak nOPC density within this segment (Fig. 6A). nOPCs in rostral and caudal segments were not detected to any appreciable level until 4 weeks of cuprizone challenge. By 6 weeks of recovery, nOPCs declined substantially in all but the rostral segment (Fig. 6A). Mature NPC-derived oligodendrocytes $\left(\mathrm{CC}^{+} \mathrm{YFP}^{+}\right.$cells) were first observed after 4 weeks of cuprizone challenge, albeit at very low densities (Fig. 6B). Large numbers of NPC-derived oligodendrocytes were evident by 6 weeks of recovery following cuprizone withdrawal, with the highest densities observed in the rostral segment, as described earlier.

Parenchymal OPCs (PDGFR $\alpha^{+} \mathrm{YFP}^{-}$cells) within the CC of TAM/cuprizone Nestin:YFP mice were at their highest density after 4 weeks of cuprizone challenge and returned to baseline densities by 6 weeks of recovery (Fig. 6 C). Interestingly, at the 4 week cuprizone time point, pOPC densities in each segment were lowest in regions adjacent to the SVZ, and highest in medial and lateral regions, the inverse pattern to that of NPC-derived OPCs at the same time point (Fig. $6 A$ ). $\mathrm{YFP}^{-}$oligodendrocytes $\left(\mathrm{CC}^{+}\right.$ $\mathrm{YFP}^{-}$cells) were all but absent from the CC at 2 and 3 weeks of

\section{$\leftarrow$}

Figure 6. Spatiotemporal analysis of oligodendrogenesis by NPC-derived cells and pOPCderived cells during cuprizone-induced demyelination and remyelination. $\boldsymbol{A}-\boldsymbol{D}$, Mediolateral distributions of cell types in the rostral, middle, and caudal segments of the CC of TAM/ cuprizone-challenged Nestin:YFP mice. Analyses were performed in mice collected after 2, 3, and 4 weeks of cuprizone challenge, and after 6 weeks recovery following a 6 week cuprizone challenge. $\boldsymbol{A}-\boldsymbol{D}$, Regional densities are plotted for YFP ${ }^{+}$NPC-derived nOPCs expressing PDGFR $\alpha(\boldsymbol{A}) ; \mathrm{YFP}^{+} \mathrm{NPC}$-derived oligodendrocytes expressing CC1 (B); YFP ${ }^{-}$pOPCs expressing PDGFR $\alpha(\boldsymbol{C})$; and YFP ${ }^{-}$oligodendrocytes expressing CC1 (D). E, F, Density of CC1 ${ }^{+}$oligodendrocytes $(\boldsymbol{E})$ and PDGFR $\alpha^{+}$progenitors $(\boldsymbol{F})$ derived from either pOPCs (YFP ${ }^{-}$, gray) or NPCS (YFP ${ }^{+}$, green) in the region of the (C adjacent to the SVZ. TAM/cuprizone-challenged Nestin: YFP mice were examined at 2,3, and 4 weeks of cuprizone challenge and after 6 weeks recovery following a 6 week cuprizone challenge and compared with unchallenged controls. Two-way ANOVA was used to compare the mean density of YFP ${ }^{+}$versus YFP ${ }^{-}$cells at each time point, and within each segment of the $\mathrm{CC}\left({ }^{*} p<0.05,{ }^{* *} p<0.01,{ }^{* *} p<0.001,{ }^{* * * *} p<0.0001\right)$. Mean \pm SEM values are shown. cuprizone challenge, apart from very low densities of $\mathrm{CC}^{+}$ $\mathrm{YFP}^{-}$cells in the medial aspects of the caudal CC at 2 weeks cuprizone (Fig. 6D). The failure to detect $\mathrm{CC}^{+}{ }^{+}$oligodendrocytes within the CC from 2 weeks of cuprizone challenge is consistent with the rapid decline in oligodendrocyte density previously described in this model (Hesse et al., 2010).

YFP $^{-}$oligodendrocytes first reappeared after 4 weeks of cuprizone challenge and were at highest density adjacent to the dorsolateral corner of the SVZ (Fig. 6D), where pOPCs were at lowest density (Fig. 6C). The reappearance of YFP ${ }^{-}$ oligodendrocytes adjacent to the SVZ at the 4 week time point in the very region where pOPCs were least abundant could potentially be explained by an earlier recruitment of pOPCs, and their subsequent differentiation into $\mathrm{CC} 1{ }^{+}$oligodendrocytes between 3 and 4 weeks of cuprizone challenge, which was yet to occur in medial and lateral positions. To directly examine this possibility, we traced the fate of pOPC-derived $\mathrm{YFP}^{+}$ cells in Pdgfra:YFP mice that were challenged with cuprizone for 4 weeks and received the thymidine analog EdU in their drinking water during the fourth week (Fig. $7 A-C$ ). The vast majority of $\mathrm{CC}^{+}$cells were $\mathrm{EdU}^{-} \mathrm{YFP}^{-}$(Fig. $7 A$, white arrows, $C$, quantification), indicating that they do not derive from PDGFR $\alpha^{+}$cells, nor do they derive from cells that had undergone mitosis within the previous $7 \mathrm{~d}$. A small fraction of the $\mathrm{CC}^{+}{ }^{+}$cells were $\mathrm{EdU}^{+} \mathrm{YFP}^{-}$(Fig. $7 A$, yellow arrows, $C$, quantification), likely reflecting the few NPC-derived $\mathrm{CC} 1^{+}$ cells that are first detected in TAM/cuprizone Nestin:YFP mice at this time point (Fig. $6 B$ ). Importantly, the data reveal that very few of the $\mathrm{CC}{ }^{+}$cells in TAM/cuprizone Pdgfra:YFP mice observed after 4 weeks of cuprizone challenge expressed YFP. Since the recombination efficiency of the YFP reporter in PDGFR $\alpha^{+}$cells was $59.1 \%$ in this cohort, we can therefore conclude that few of the $\mathrm{CC} 1^{+}$cells observed after 4 weeks of cuprizone challenge could have derived from pOPCs, regardless of whether they had divided before differentiation or differentiated directly into $\mathrm{CC}^{+}{ }^{+}$cells without prior cell division. On this basis, we can also conclude that only a very small fraction of the $\mathrm{CC}^{+}{ }^{+} \mathrm{EdU}^{-} \mathrm{YFP}^{-}$cells could have potentially derived from the non-recombined fraction of PDGFR $\alpha^{+}$cells. We can also exclude the possibility that $\mathrm{CC}^{+}{ }^{+} \mathrm{EdU}^{-} \mathrm{YFP}^{-}$cells in Pdgfra:YFP mice derive principally from postmitotic NPC-derived progenitors by week 4 since the $\mathrm{CC}^{+}{ }^{+} \mathrm{EdU}^{-} \mathrm{YFP}^{-}$cells in Pdgfra:YFP mice are far too numerous compared with the density of $\mathrm{CC}^{+}{ }^{+} \mathrm{YFP}^{+}$cells in Nestin:YFP mice at the 4 week time point (Fig. $6 B$ ). The most parsimonious explanation is that the majority of $\mathrm{CC}^{+}{ }^{+}$cells that emerge after 4 weeks of cuprizone challenge are preexisting postmitotic oligodendrocytes in which the CC1 antigen is either transiently downregulated and re-expressed after 4 weeks cuprizone, as described for other myelin proteins in the cuprizone model (Morell et al., 1998; Hesse et al., 2010), or in which the CC1 epitope is transiently masked from immunohistochemical detection. These $\mathrm{CC}^{+}{ }^{+}$cells would not be expected to express YFP in either transgenic line since they would not have expressed the PDGFRa-CreER ${ }^{T 2}$ or Nestin$C r e E R^{T 2}$ transgenes at the time of tamoxifen gavage. In support of this view, the density and distribution of $\mathrm{CC}^{+}{ }^{+} \mathrm{EdU}^{-}$ $\mathrm{YFP}^{-}$cells in 4 week cuprizone-challenged Pdgfra:YFP mice (Fig. $7 C$ ) was very similar to that of $\mathrm{CC}^{+}{ }^{+} \mathrm{YFP}^{-}$cells in identically challenged Nestin:YFP mice examined after 4 weeks of cuprizone challenge (Fig. 6D). Whether or not these reemergent $\mathrm{CC}^{+}{ }^{+}$cells had maintained their myelin before the fourth week of cuprizone challenge and whether they continue 
A

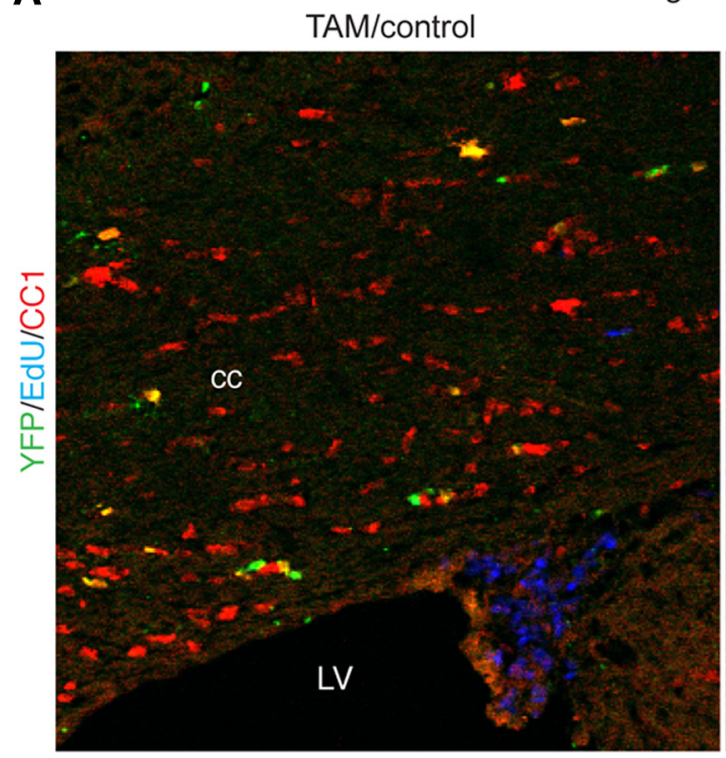

Pdgfra:YFP mice
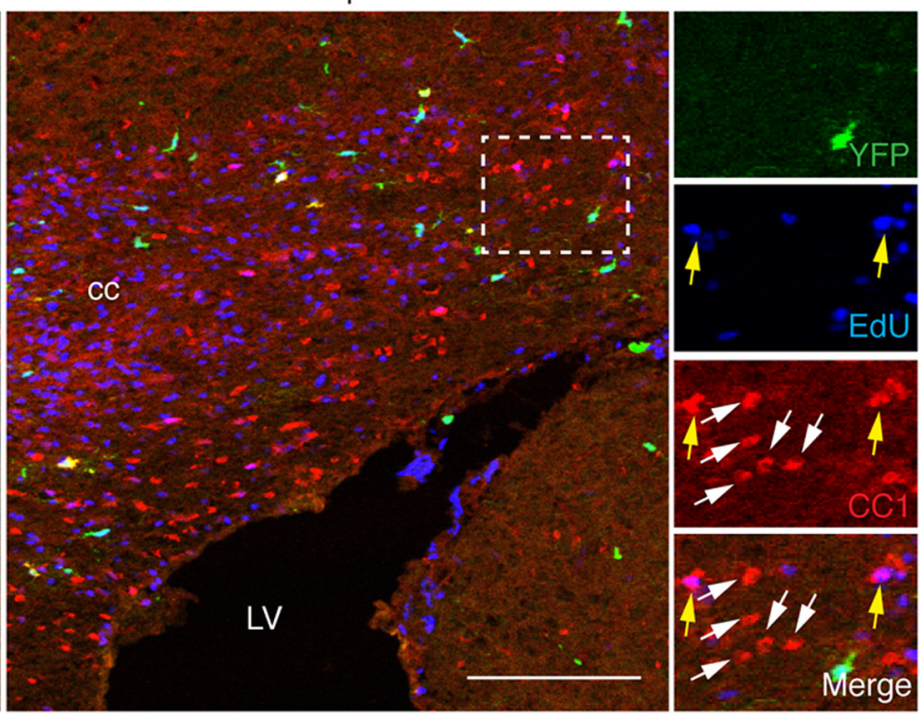

B

Rostral

Middle

Caudal
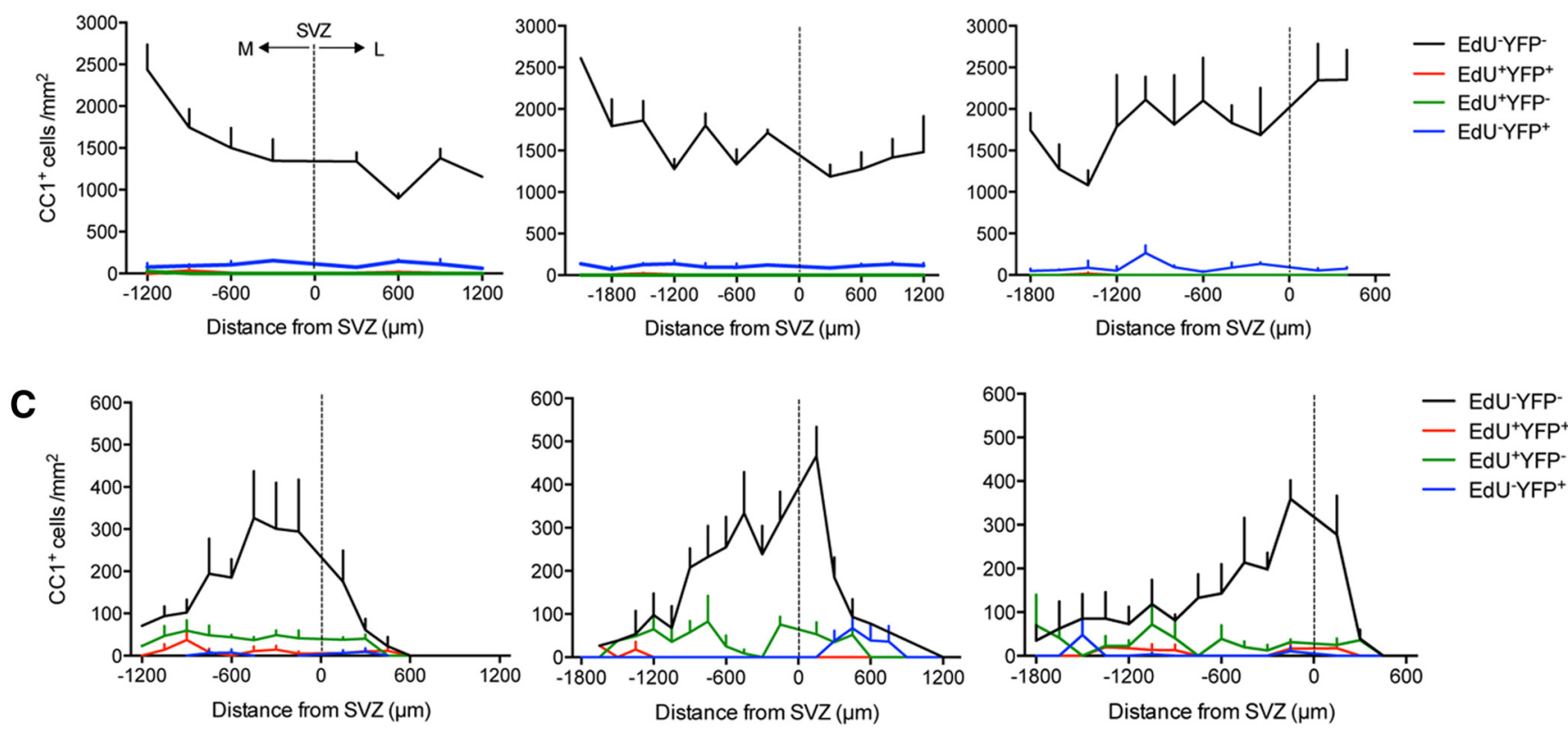

Figure 7. Identification of pre-existing oligodendrocytes adjacent to the SVZ at 4 weeks of cuprizone challenge in Pdgfra:YFP mice. A, Confocal micrographs of the rostral CC of TAM/control and TAM/cuprizone Pdgfra:YFP mice labeled with antibodies against YFP and CC1, and stained for the thymidine analog EdU, which was administered during the fourth week of cuprizone challenge. Right, High magnification of the boxed region reveals EdU ${ }^{+}$and EdU ${ }^{-}$oligodendrocytes (yellow and white arrowheads, respectively). $B, C$, Mediolateral distributions of newly generated (EdU ${ }^{+}$) versus pre-existing ( $\left(\mathrm{EdU}^{-}\right.$) oligodendrocytes in the rostral, middle, and caudal segments of the CC of TAM/control (B) versus TAM/cuprizone Pdgfra:YFP mice (C). LV, Lateral ventricle. Scale bar, 120 $\mu \mathrm{m}$. Mean \pm SEM values are shown.

to maintain or alternatively generate new myelin after the fourth week of cuprizone challenge cannot be ascertained from our data.

Additional data support the conclusion that most of the $\mathrm{CC}^{+}{ }^{+}$that appear after 4 weeks of cuprizone challenge derive from pre-existing oligodendrocytes. Since these cells were most abundant adjacent to the SVZ, we focused on the cellular dynamics in this region, which was also the region to which NPCderived oligodendroglia were recruited in greatest number. We quantified mean cell densities within an $1800 \mu \mathrm{m}$ region of the CC spanning $900 \mu \mathrm{m}$ both medial and lateral to the dorsolateral corner of the SVZ (Fig. 6E,F). Stacked histograms representing the $\mathrm{YFP}^{+}$and $\mathrm{YFP}^{-}$subsets of $\mathrm{CC}^{+}{ }^{+}$oligodendrocytes (Fig. $6 E$ ) and PDGFR $\alpha^{+}$cells (Fig. $6 F$ ) were plotted for each rostrocaudal segment. We noted that the total density of $\mathrm{CC}^{+}{ }^{+}$oligodendrocytes quantified at the 6 week recovery time point did not equate with the density of newly generated $\mathrm{CCl}^{+}$oligodendrocytes identified by fate mapping NPCs and pOPCs. Specifically, analysis of the Nestin:YFP mice had shown that in the rostral segment of the CC adjacent to the SVZ, $334.2 \pm 103.9$ cells $/ \mathrm{mm}^{2} \mathrm{CC}{ }^{+}$ cells were $\mathrm{YFP}^{-}$, suggesting that these cells were not derived from NPCs (Fig. 6E). However, in the TAM/cuprizone-challenged Pdgfra:YFP mice only $70.5 \pm 30.8 \mathrm{CC}^{+}$cells $/ \mathrm{mm}^{2}$ were $\mathrm{YFP}^{+}$in the corresponding region (Fig. $5 E$ ). Since the mean recombina- 

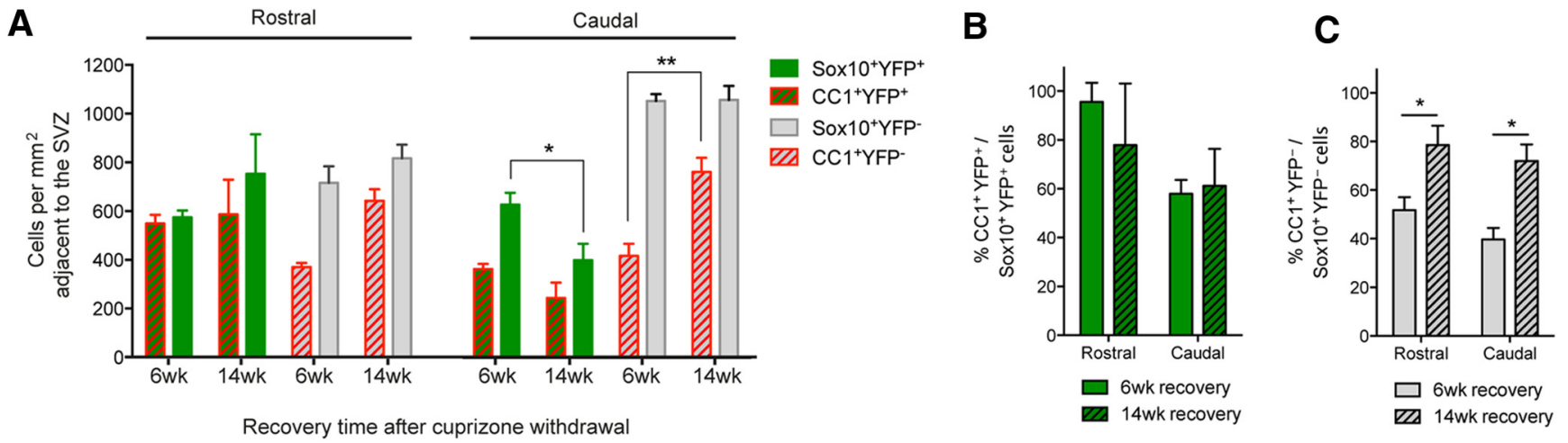

Figure 8. NPC-derived oligodendrocytes are maintained long term after cuprizone challenge. $A$, Density of YFP ${ }^{+}$and YFP ${ }^{-}$subpopulations of $\mathrm{CC}^{+}{ }^{+}$oligodendrocytes and Sox $10^{+}$oligodendroglia adjacent to the SVZ in rostral and caudal segments of the CC of Nestin:YFP mice assessed at 6 and 14 weeks of recovery after cuprizone withdrawal. $\boldsymbol{B}$, The relative density of NPC-derived CC ${ }^{+}$ oligodendrocytes expressed as a percentage of NPC-derived Sox $10^{+}$oligodendroglia revealed that differentiation did not differ between rostral or caudal segments between 6 and 14 weeks of recovery. Two-way ANOVA with Bonferroni's post hoc analysis did not reveal any statistically significant effects. $C$, The relative density of pOPC-derived $\mathrm{CC} 1^{+}$oligodendrocytes expressed as a percentage of pOPC-derived Sox $10^{+}$oligodendroglia was significantly higher at 14 weeks compared with 6 weeks of recovery in rostral and caudal segments. Two-way ANOVA with Bonferroni's posthoc analysis revealed an overall statistically significant effect of the recovery time point $\left({ }^{* *} p<0.01\right)$, and a specific effect of the recovery time point for both rostral and caudal segments $\left({ }^{*} p<0.05\right)$.

tion efficiency in Pdgfra:YFP mice was 59.1\%, we can extrapolate that fate mapping of all PDGFR $\alpha^{+}$cells would have accounted for $119.3 \pm 52.1 \mathrm{CC}^{+}$cells $/ \mathrm{mm}^{2}$, had the recombination of pOPCs cells been $100 \%$ efficient. This result implies that up to $214.9 \mathrm{CC}^{+}$cells $/ \mathrm{mm}^{2}$ in this region were generated from preexisting oligodendrocytes that either transiently downregulate the $\mathrm{CC} 1$ antigen then re-express the protein by 4 weeks of cuprizone challenge, or that the CC1 epitope in these cells is transiently masked from immunohistochemical detection. We also identified that it is the distribution of pOPCs quantified at 4 weeks of cuprizone challenge, rather than that of the pOPC-derived oligodendrocytes observed at the same time point that predicts the subsequent distribution profile of pOPC-derived oligodendrocytes after 6 weeks of recovery (Fig. 6C,D).

\section{Oligodendrogenesis adjacent to the SVZ subsequent to 4 weeks of cuprizone challenge is mediated by NPCs}

In TAM/cuprizone Nestin:YFP mice, the density of $\mathrm{CC} 1^{+} \mathrm{YFP}^{-}$ cells (pOPC-derived oligodendrocytes) in the region of the CC adjacent to the SVZ was similar at both the 4 week time point and the 6 week recovery time point (Fig. $6 E$ ). We conclude that the subsequent restoration of $\mathrm{CC}^{+}$oligodendrocytes to control density in both rostral and caudal regions, as identified at the 6 week recovery time point, is due almost exclusively to the addition of NPC-derived oligodendrocytes (Fig. 6E).

After 4 weeks of cuprizone challenge, the density of PDGFR $\alpha^{+}$cells of pOPC origin in the region adjacent to the SVZ exceeded that of PDGFR $\alpha^{+}$cells of NPC origin (Fig. $6 F$ ). However, pOPCs do not appear to contribute further to the generation of new $\mathrm{CC}^{+}{ }^{+}$oligodendrocytes beyond 4 weeks of cuprizone challenge except possibly in the middle segment of the CC (Fig. 6E,F). Interestingly, whereas pOPC densities reduced to control levels by 6 weeks of recovery, the population of newly recruited PDGFR $\alpha^{+}$ $\mathrm{YFP}^{+} \mathrm{NPCs}$ remained elevated at this time point, resulting in an increase in the total density of PDGFR $\alpha^{+}$cells in this region of the CC relative to control mice (Fig. $6 F$ ). Thus, PDGFR $\alpha^{+}$cells of NPC origin accounted for a significant proportion of the total PDGFR $\alpha^{+}$ cell population adjacent to the SVZ in each segment in the rostrocaudal axis at the 6 week recovery time point (rostral, $58.8 \pm 3.2 \%$; middle, $42.3 \pm 8.7 \%$; caudal $39.2 \pm 14.2 \%$ ).

\section{NPC-derived oligodendrocytes persist long term after cuprizone withdrawal}

We next examined whether the contribution of SVZ-derived NPCs to oligodendrogenesis was sustained long-term after cuprizone withdrawal. The density of $\mathrm{CC}^{+}{ }^{+} \mathrm{YFP}^{+}$cells adjacent to the SVZ in the Nestin:YFP mice at 14 weeks recovery was similar to that observed at the 6 week recovery time point, in both rostral and caudal segments (Fig. $8 A$ ). The density of total NPC-derived oligodendroglia (Sox $10^{+} \mathrm{YFP}^{+}$cells) was reduced in the caudal segment at 14 weeks relative to 6 weeks of recovery $(p<0.05)$. One explanation could be that some immature NPC-derived oligodendroglia that fail to differentiate into mature oligodendrocytes in the caudal segment by 6 weeks of recovery could undergo apoptotic cell death by 14 weeks recovery.

In contrast to the similar densities of NPC-derived oligodendrocytes at 6 and 14 weeks recovery, the density of pOPC-derived oligodendrocytes $\left(\mathrm{CCl}^{+} \mathrm{YFP}^{-}\right.$cells) increased in both the rostral and caudal segments from 6 to 14 weeks recovery, although the difference was only statistically significant in the caudal segment $(p<0.001$; Fig. $8 A)$. Since the total density of Sox $10^{+}$ $\mathrm{YFP}^{-}$cells in the caudal segment adjacent to the SVZ remained unchanged between 6 and 14 weeks recovery, and the finding that pOPC densities at 6 weeks recovery were equivalent to control levels (Fig. 6F), we can conclude that many of the newly generated pOPC-derived oligodendrocytes were likely to have derived from the existing pool of premyelinating oligodendroglia already present at the 6 week recovery time point.

The percentage of NPC-derived oligodendroglia (Sox $10^{+}$ $\mathrm{YFP}^{+}$cells) that expressed CC1 was higher rostrally at both 6 and 14 weeks of recovery (Fig. $8 \mathrm{~B}$ ), and the fraction of oligodendroglia that expressed $\mathrm{CC} 1$ in the caudal segment did not change from 6 to 14 weeks of recovery. In contrast, whereas the population of pOPC-derived oligodendroglia at 6 weeks of recovery comprised many immature cells in both rostral and caudal segments, a significantly higher percentage of the population had matured into $\mathrm{CCl}^{+} \mathrm{YFP}^{-}$oligodendrocytes by 14 weeks of recovery (Fig. 8C). Collectively, these data reveal that NPC-derived oligodendroglia in the caudal CC are subject to a prolonged impairment in cellular maturation, whereas pOPCs undergo a transient delay in maturation that affects both rostral and caudal segments to a similar degree. 

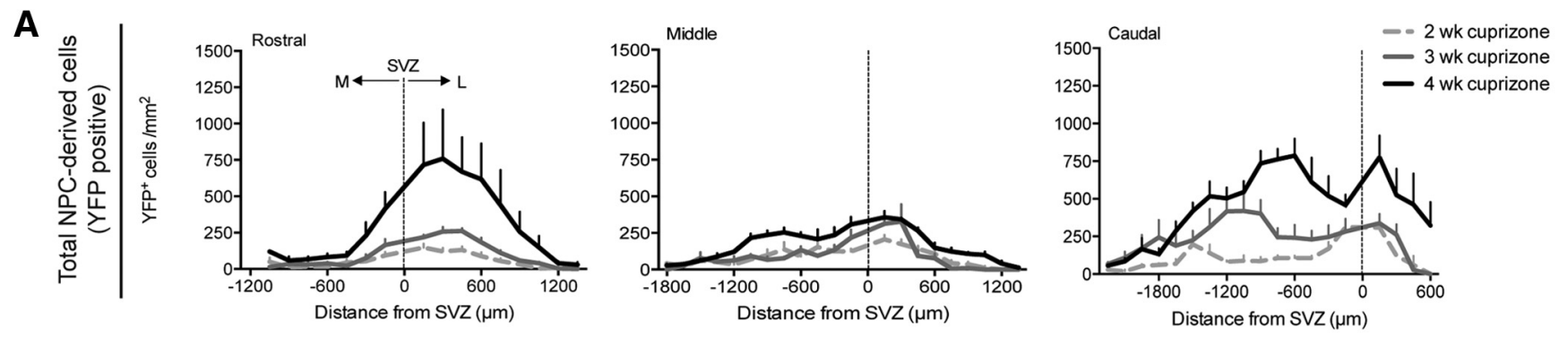

B

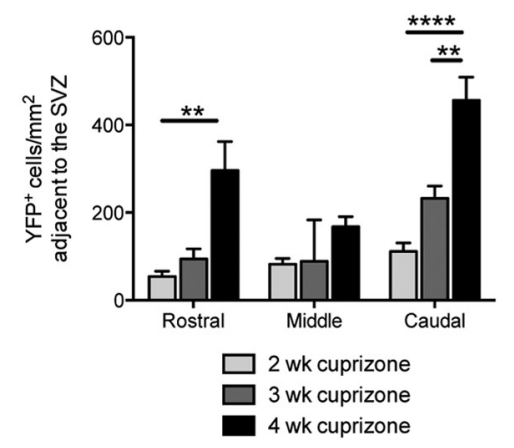

C

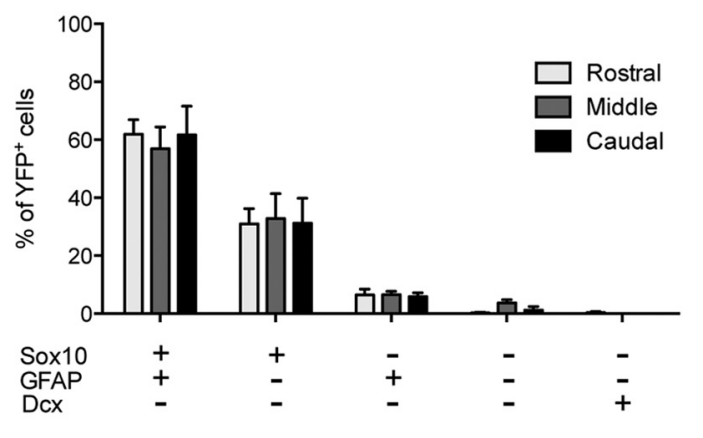

D

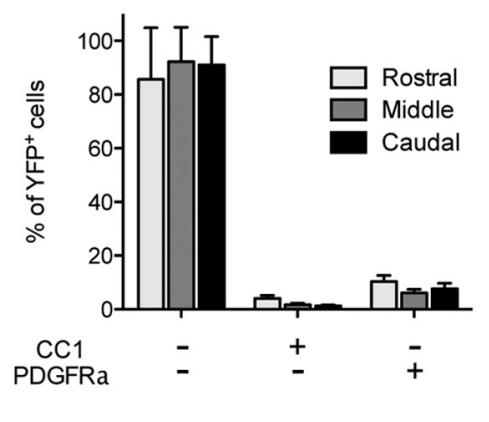

Figure 9. The repertoire of NPC-derived cells within the CC during cuprizone-induced demyelination. $A$, Mediolateral distributions of the total population of YFP ${ }^{+}$NPC-derived cells in the rostral, middle, and caudal CC of TAM/cuprizone-challenged Nestin:YFP mice at 2, 3, and 4 weeks of cuprizone challenge. B, Quantification of total YFP ${ }^{+}$NPC-derived cells in the CC adjacent to the SVZ revealed a significant recruitment of cells in the rostral and caudal CC starting at 2 weeks of cuprizone challenge, with no significant increase being observed in the middle CC. Two-way ANOVA was used to compare the mean density of YFP ${ }^{+}$cells among 2,3 , and 4 weeks of cuprizone challenge for each segment of the $C\left({ }^{* *} p<0.01,{ }^{* * * *} p<0.0001\right)$. C, Percentage of YFP ${ }^{+}$cells expressing Sox10, GFAP, and/or Dcx in the rostral, middle, and caudal CC of TAM/cuprizone Nestin:YFP mice examined after 4 weeks of cuprizone challenge. D, Plot of the percentage of YFP ${ }^{+}$NPC-derived cells that express $\mathrm{CC} 1$ or PDGFR $\alpha$ after 4 weeks of cuprizone challenge. Mean \pm SEM values are shown.

NPCs are recruited to the CC early after cuprizone challenge, but the generation of NPC-derived $\mathrm{CC}^{+}$oligodendrocytes is delayed

The inability of NPCs to generate $\mathrm{CC}^{+}$oligodendrocytes until after 4 weeks of cuprizone challenge did not reflect a delayed NPC response to cuprizone challenge since SVZ-derived $\mathrm{YFP}^{+}$cells entered the CC as early as 2 weeks after the initiation of a cuprizone challenge (Fig. 9A,B). The density of $\mathrm{YFP}^{+}$cells in the rostral and caudal CC of Nestin:YFP mice progressively increased between 2 and 4 weeks of cuprizone challenge, whereas increases in the middle segment of the CC were not as marked (Fig. 9B). The density of NPC-derived cells along the mediolateral axis of the CC was highest in regions adjacent to the SVZ after 4 weeks of cuprizone challenge (Fig. 9A), and the cellular identity of these cells was similar at all rostrocaudal segments. Within the CC at this time point, most $\mathrm{YFP}^{+}$cells $(60.2 \pm 7.5 \%)$ coexpressed both GFAP and Sox10 (Fig. 9C), about one-third (31.7 \pm 8.0\%) expressed Sox 10 only, and the remainder were positive for either GFAP or for YFP alone. Very few $\mathrm{Dcx}^{+} \mathrm{YFP}^{+}$cells were observed at this time point across the entire CC. Immunohistochemistry performed on parallel sections revealed that oligodendrocyte production by NPCs at the 4 week time point was minimal, with $2.3 \pm 0.9 \%$ of $\mathrm{YFP}^{+}$cells coexpressing CC1. Only $8.0 \pm 1.2 \%$ of the YFP ${ }^{+}$cells coexpressed PDGFR $\alpha$ (Fig. 9D), whereas $21.4 \%$ of the cells were Sox $10^{+} \mathrm{GFAP}^{-}$PDGFR $\alpha^{-} \mathrm{CC}^{-} \mathrm{YFP}^{+}$. Collectively, these data indicate that NPC recruitment is evident from at least as early as 2 weeks of cuprizone challenge and increases substantially by 4 weeks but that very few mature oligodendrocytes are generated by NPCs during this period. Oligodendrogenesis by NPCs is largely restricted to the period subsequent to the fourth week of cuprizone challenge.
NPC-derived oligodendrocytes exhibit extensive remyelination capacity and re-establish nodes of Ranvier within the remyelinating $\mathrm{CC}$

Our time-course and fate-mapping studies revealed dynamic responses of NPCs to cuprizone-induced demyelination, which results in the recruitment and differentiation of large numbers of new NPC-derived oligodendrocytes within the CC subsequent to the fourth week of cuprizone challenge. We next sought to investigate whether NPC-derived oligodendrocytes generate new myelin in the course of CNS remyelination. The Rosa26-eYFP strain is unsuitable for this purpose because cytosolic YFP is excluded from compact myelin (Young et al., 2013). We therefore crossed Nestin-CreER $R^{T 2}$ line 5-1 mice to the $m T m G$ strain, which exhibits constitutive expression of membrane targeted tdTomato (mT) but converts to expression of mGFP following Cre-mediated excision of $\mathrm{mT}$ and a downstream STOP cassette (Fig. 10A; Muzumdar et al., 2007). Nestin:mTmG mice were challenged with $\mathrm{TAM} /$ control or TAM/cuprizone for 6 weeks followed by 6 weeks of recovery (Fig. 10B-E). Consistent with previous results using Nestin:YFP mice, $\mathrm{mGFP}^{+}$cells were almost never observed in Oil/control Nestin:mTmG mice, whereas Oil/cuprizone mice assessed at 6 weeks of recovery exhibited occasional $\mathrm{mGFP}^{+}$cells in the CC, SVZ, and subgranular zone (SGZ) of the dentate gyrus (data not shown), reflecting low-level tamoxifen-independent recombination associated with cuprizone challenge. In TAM/ control mice, mGFP labeling was restricted to the SVZ and SGZ neurogenic niches (Fig. 10B). In contrast, TAM/cuprizone mice exhibited intense $\mathrm{mGFP}$ expression within the CC in addition to the SVZ and SGZ (Fig. 10C-E). The TAM/cuprizone mice exhibited a rostrocaudal gradient of mGFP expression, consistent with 
A

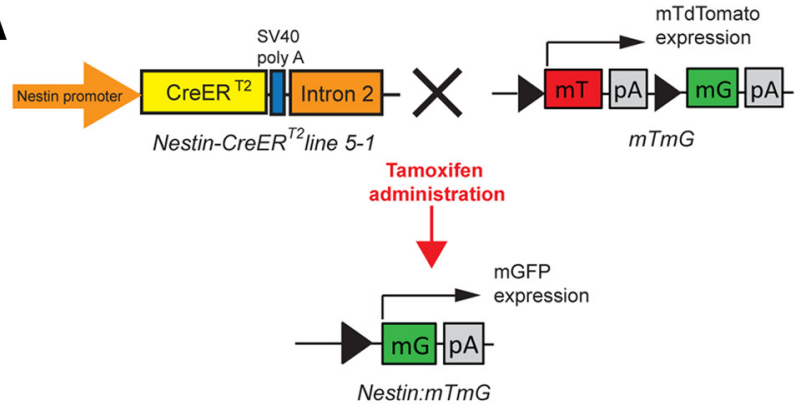

B

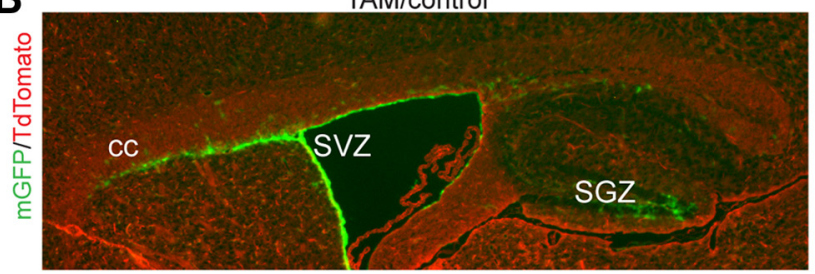

C

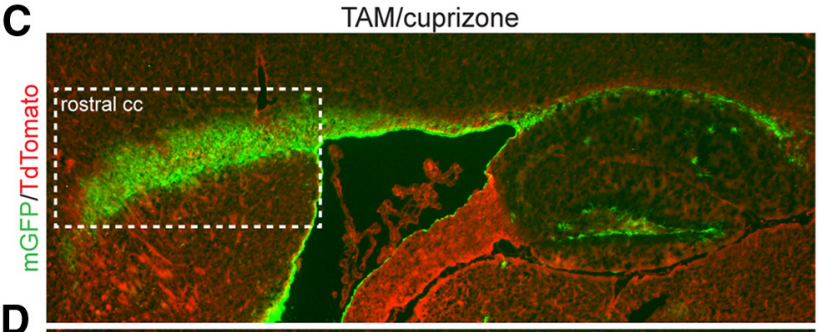

D
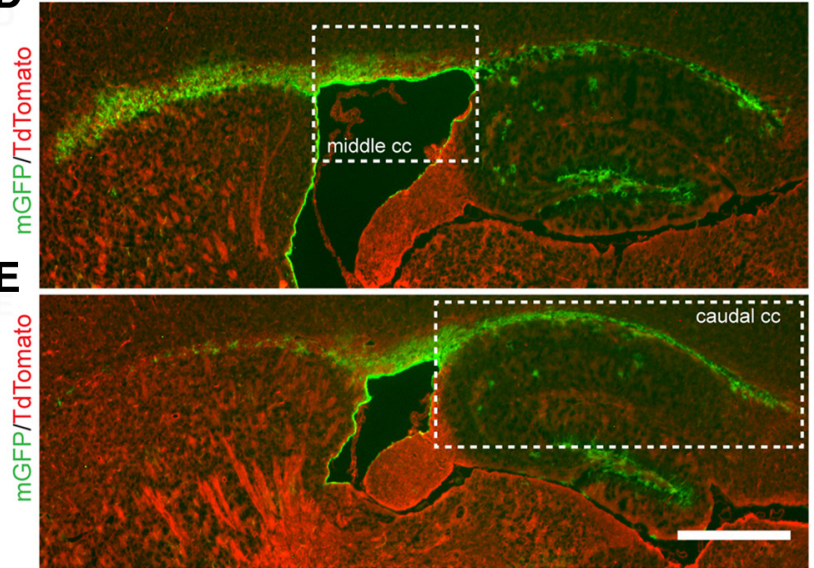

Figure 10. mGFP labeling of the membranes of NPC-derived cells after Cre-mediated recombination. $A$, Schematic representation of the transgenic alleles in Nestin:mTmG mice showing tamoxifen-responsive recombination of the Rosa26-mImG allele to induce mGFP expression. $\boldsymbol{B}$, Parasagittal section ( $0.84 \mathrm{~mm}$ lateral to bregma) of the $\mathrm{CC}$ of a TAM/control Nestin:mT/mG mouse at the 6 week recovery time point immunolabeled with an antibody against GFP. In the control group, mGFP labeling was restricted in the neurogenic niches of SVZ and SGZ, with no expression in the CC. C-E, mGFP-labeled parasagittal sections (range, $0.84-2.40 \mathrm{~mm}$ lateral to bregma) of the (C of a TAM/cuprizone Nestin:mTmG mouse assessed at 6 weeks of recovery after cuprizone withdrawal. Dashed line represents the boundaries of nominated rostral, middle, and caudal segments of the CC. Scale bars: $\boldsymbol{B}-\boldsymbol{E}, 400 \mu \mathrm{m}$.

results obtained using Nestin:YFP mice. Specifically, mGFP labeling was greatest in the rostral CC adjacent to the SVZ.

To determine whether NPC-derived oligodendrocytes were capable of remyelinating callosal axons, we assessed sagittal sections containing the rostral and caudal $\mathrm{CC}$ for the expression of GFP, the myelin proteins MBP and CNPase, and neurofilament (SMI312) to identify axons. Confocal micrographs revealed an abundance of $\mathrm{mGFP}^{+}$myelin rings coexpressing $\mathrm{MBP}$ or $\mathrm{CN}-$
Pase that ensheathed SMI312-labeled axons (Fig. 11A,B). Quantification revealed a 16 -fold higher density of $\mathrm{mGFP}^{+}$myelin rings in rostral versus caudal regions adjacent to the SVZ (Fig. 11C). To examine whether NPC-derived oligodendrocytes re-established the normal integrity of nodes of Ranvier and adjacent paranodes, coronal sections of the rostral CC were labeled with antibodies against GFP, the nodal marker $\mathrm{Na}_{\mathrm{v}} 1.6$, and either CNPase (Fig. $11 D$ ) or the paranodal marker Caspr (Fig. $11 E-G$ ). The majority of nodes $(62.1 \pm 3.7 \%)$ in rostral segments adjacent to the SVZ were flanked by $\mathrm{mGFP}^{+}$myelin that ensheathed either one or both of the paranodes, as confirmed by serial confocal scans in the $z$-axis (Fig. $11 G$, white arrowheads, $H$, quantification). This analysis therefore provided direct evidence that NPC-derived oligodendrocytes generate new myelin internodes that ensheath many of the axons in the rostral CC. As expected, we also identified many nodes that were not flanked by $\mathrm{mGFP}^{+}$segments, particularly in regions of the CC topographically removed from the rostral SVZ, implying that these axons were either myelinated by pOPC-derived oligodendrocytes or had escaped demyelination (Fig. $11 F$, yellow arrowheads).

Remyelination is more extensive in the rostral compared with the caudal corpus callosum

Our fate-mapping studies provide direct evidence that NPCderived oligodendrocytes contribute significantly to remyelination of the CC following cuprizone-induced demyelination, particularly in rostral segments adjacent to the SVZ. Analysis of myelin integrity throughout the rostrocaudal axis of the CC by both Black-Gold II and FluoroMyelin histochemistry confirmed significant demyelination after 3.5 weeks of cuprizone challenge and partial restoration of myelin by 6 weeks of recovery. To investigate the correlation between oligodendrocyte regeneration and myelin integrity in greater detail, we examined myelin ultrastructure in sagittal sections of the rostral and caudal CC of cuprizonechallenged and control wild-type mice collected at the 6 week recovery time point (Fig. 12A-C). We found that the total density of axons was not affected by cuprizone challenge in either the rostral or caudal segments (Fig. 12D, stacked histograms). However, many axons in the caudal CC of cuprizone-challenged mice remained demyelinated at the 6 week recovery time point when compared with controls (Fig. 12C,D).

\section{NPC-derived oligodendrocytes restore myelin sheaths to a normal thickness}

We next analyzed myelin thickness among the myelinated fraction of axons within each region of interest by calculating the g-ratio for small-, medium-, and large-caliber myelinated axons. This analysis revealed that in the midline of the CC, where recruitment of pOPCs was greatest, there was a significant increase in g-ratio among small- to medium-caliber axons indicative of a thin myelin sheath (Fig. 12C), often considered a hallmark of remyelination by pOPCs (Gledhill and McDonald, 1977; Blakemore and Murray, 1981). In contrast, in regions adjacent to the SVZ where NPC-derived oligodendrocytes are recruited in large numbers, the g-ratios for all axon sizes were the same for cuprizone-challenged and control mice. The only exception was that large-caliber axons in the caudal SVZ of cuprizonechallenged mice had a lower g-ratio, indicative of increased myelin thickness (Fig. 12C).

To determine whether the observed regional differences in myelin ultrastructure can be attributed to different remyelination capacities of oligodendrocytes derived from both NPCs and pOPCs, we performed immunoelectron microscopy. Rostral 

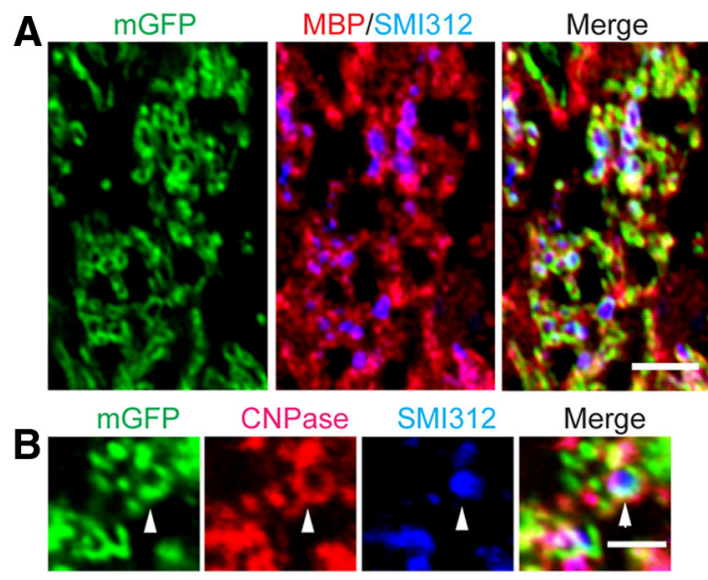

C
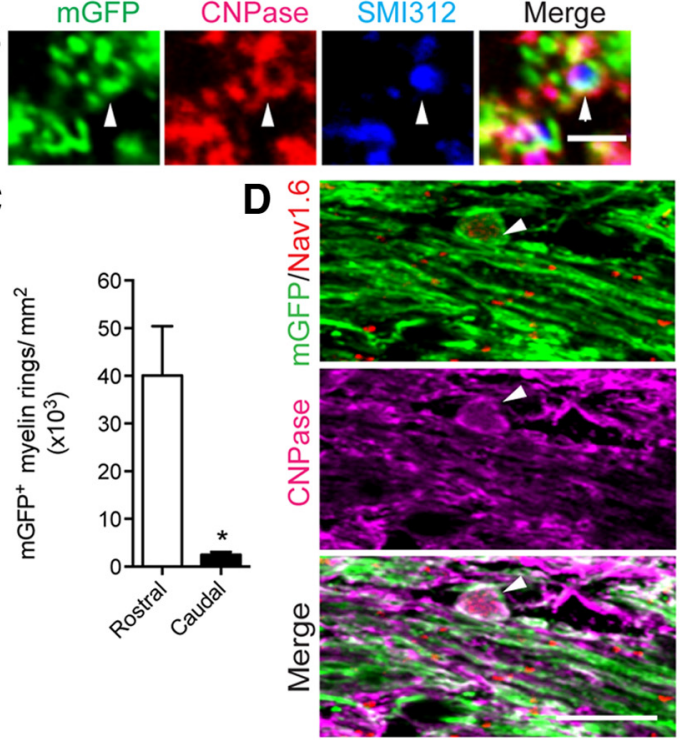

$E$

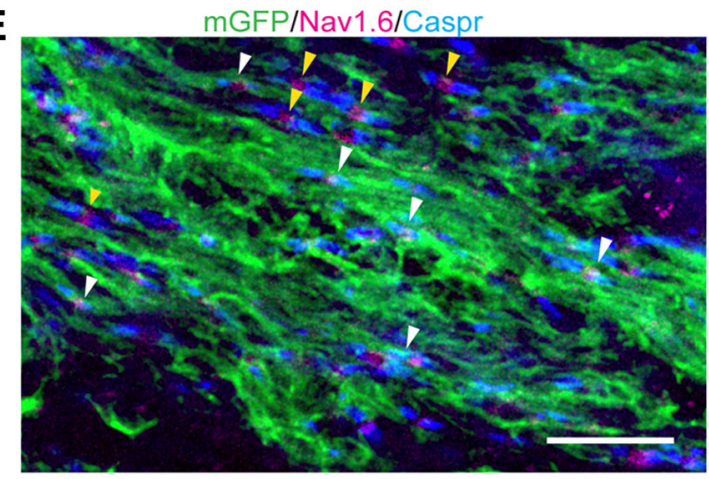

$\mathbf{F}$
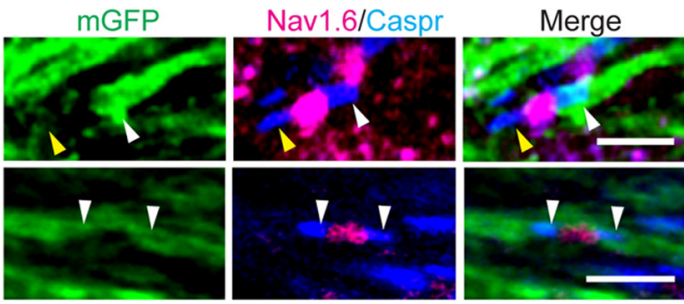

G
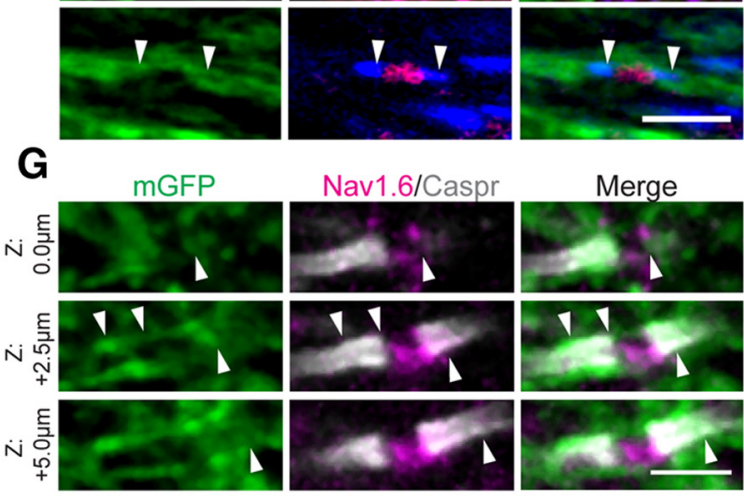

H

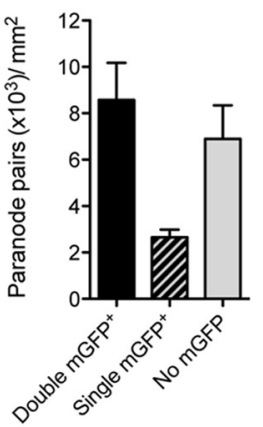

Figure 11. Myelin formation and maintenance of node integrity by mGFP-expressing NPC-derived oligodendrocytes. $\boldsymbol{A}, \boldsymbol{B}$, Triple-labeling immunohistochemistry on parasagittal sections of TAM/cuprizone Nestin:mTmG mice examined 6 weeks after cuprizone withdrawal. Confocal micrographs of the rostral CC adjacent to the SVZ revealed colocalization of GFP within many MBP- or CNPase-immunoreactive myelin rings that ensheathed SMI312-positive axons ( $\boldsymbol{B}$, white arrowhead). $\boldsymbol{C}, \mathrm{mGFP}^{+}$myelin rings were present at 16 -fold higher density in the rostral compared with the

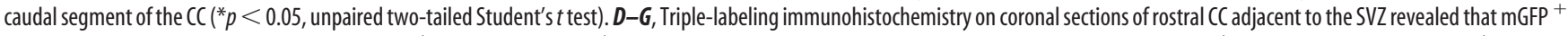
$\mathrm{NPC}$-derived oligodendrocytes ensheathed $\mathrm{Na}_{\mathrm{v}} 1.6^{+}$axons. D, An mGFP ${ }^{+} \mathrm{NPC}$-derived oligodendrocyte (white arrowhead) with numerous $\mathrm{CNPase}^{+}$processes adjacent to $\mathrm{Na}_{\mathrm{v}} 1.6^{+}{ }^{+}$nodes of Ranvier. $\boldsymbol{E}, \boldsymbol{F}, \mathrm{Na}_{\mathrm{v}} 1.6$ nodal expression in axons adjacent to Caspr-associated paranodal sites that were associated with processes either positive (white arrowheads) or negative (yellow arrowheads) for mGFP. G, Confocal z-stack images of $\mathrm{Na}_{v}$ 1.6-expressing nodal and Caspr-expressing paranodal regions of myelinated axons ensheathed by an mGFP ${ }^{+}$NPC-derived oligodendrocyte (white arrowheads). Three sequential optical slices were examined, each of which was $2.5 \mu \mathrm{m}$ thick. $\boldsymbol{H}$, Quantification of paranode pairs represented as the number of (aspr-expressing pairs double positive, single positive, or negative for mGFP. Scale bars: $\boldsymbol{A}, 3 \mu \mathrm{m} ; \boldsymbol{B}, 2 \mu \mathrm{m} ; \mathbf{D}, 20 \mu \mathrm{m} ; \boldsymbol{E}, 10 \mu \mathrm{m} ; \boldsymbol{F}, 3 \mu \mathrm{m} ; \boldsymbol{G}, 2 \mu \mathrm{m}$. Mean \pm SEM values are shown.

brain sections of TAM/cuprizone-challenged Nestin:mTmG and Pdgfra:mTmG mice collected at 6 weeks of recovery were processed by immunoelectron microscopy to gold-label mGFP epitopes within myelin. This method enabled the detection of myelin rings generated by either NPC- or pOPC-derived oligodendrocytes using tissue from Nestin:mTmG and Pdgra:mTmG mice, respectively (Fig. 13 B,C). Significantly fewer gold particles were detected on the cilia of ependymal cells and neural stem cells lining the lateral ventricles of TAM/cuprizone-challenged Nestin-
CreER ${ }^{T 2}$ single-transgenic mice (negative control), compared with Nestin:mTmG mice (Fig. 13A). Remarkably, NPC-derived oligodendrocytes adjacent to the SVZ produced thicker myelin compared to that produced by pOPC-derived oligodendrocytes examined at the midline (Fig. 13B,C). This was confirmed by g-ratio analysis, which revealed that $\mathrm{GFP}^{+}$myelinated axons in the Nestin:mTm $G$ mice had significantly lower g-ratios compared with the $\mathrm{GFP}^{+}$myelinated axons of Pdgfra:YFP mice [Fig. 13D; significant difference in $y$-intercept of lines of best fit $(p<$ 
A

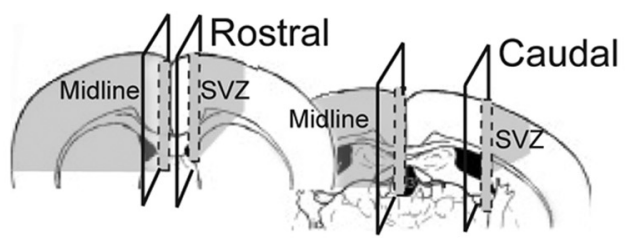

$+0.98 \mathrm{~mm}$

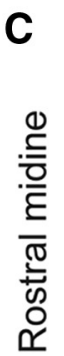
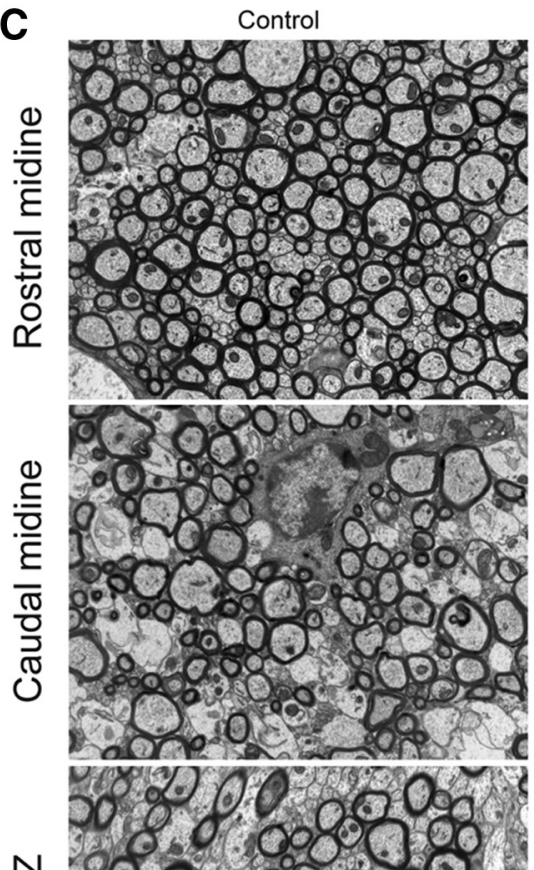

今 00100000

क 0.000000

त $00.0 \% 0000000$

范

으
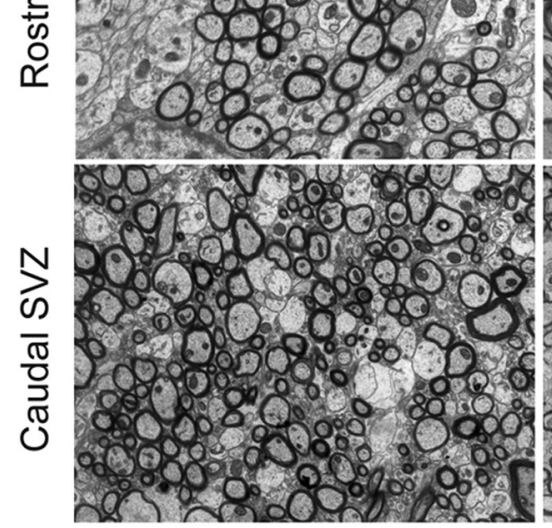

D
B

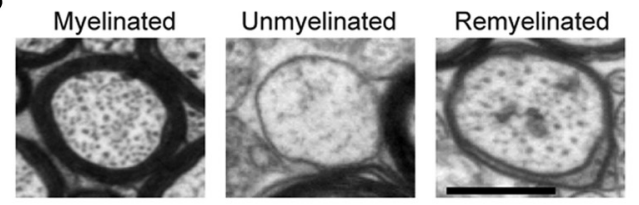

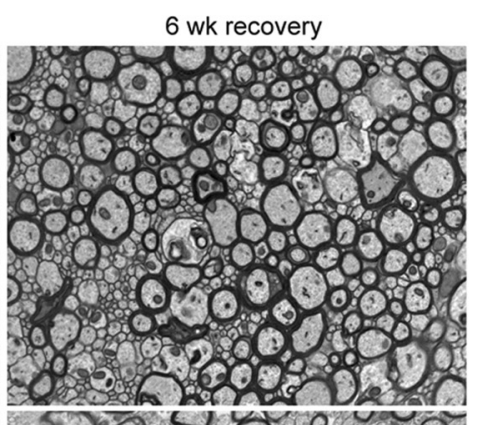
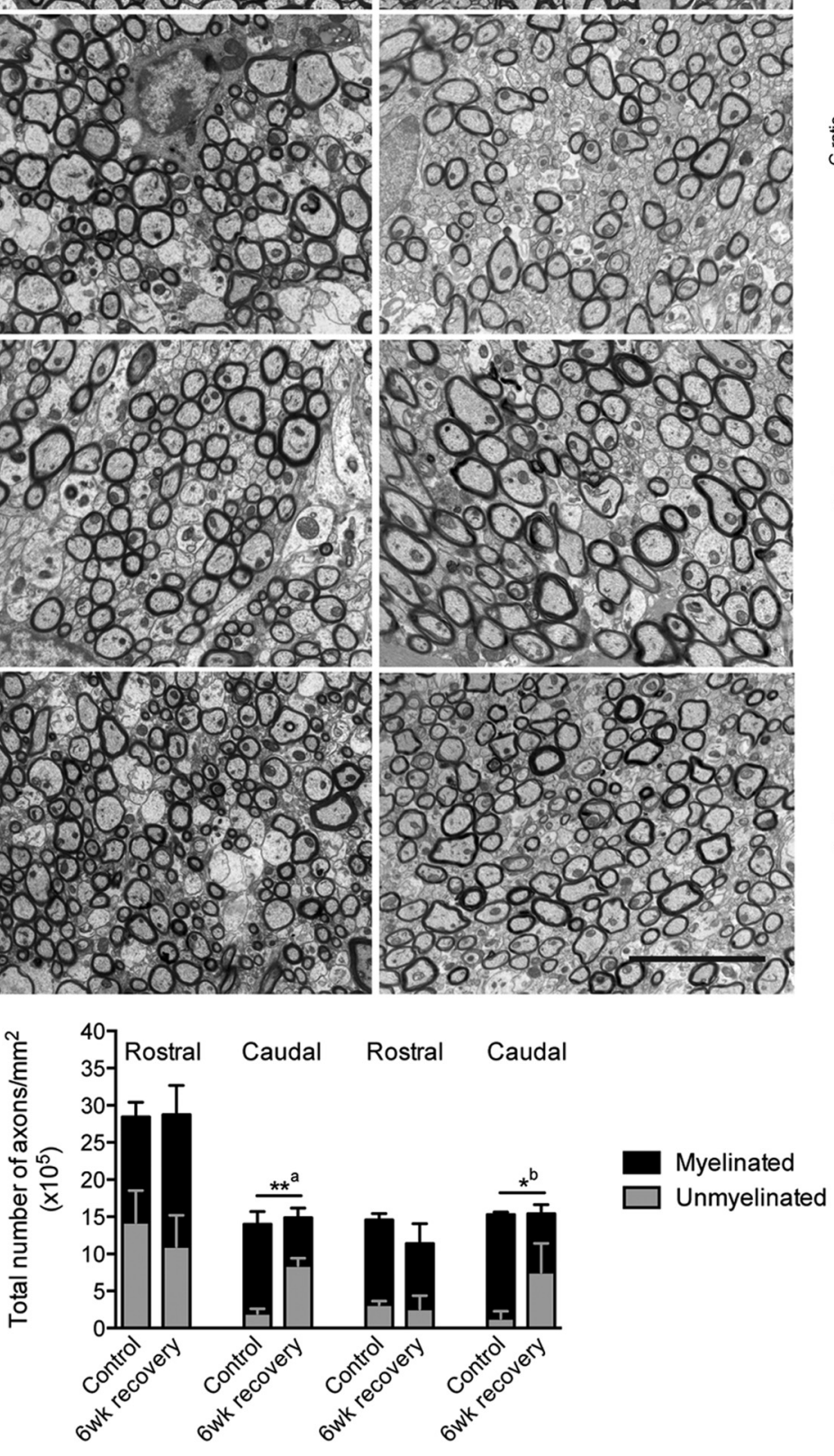
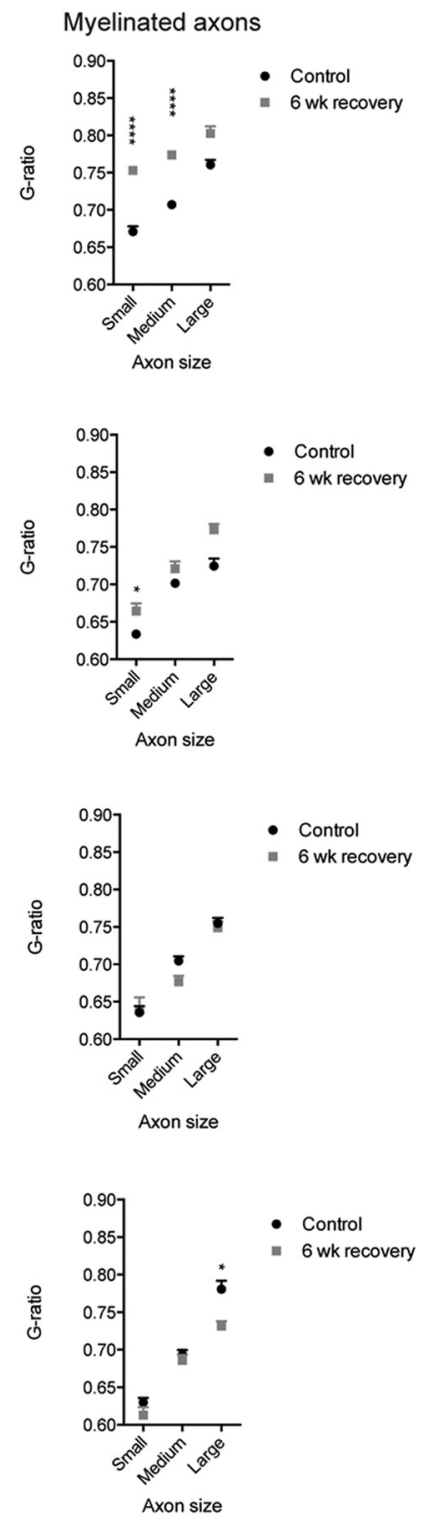

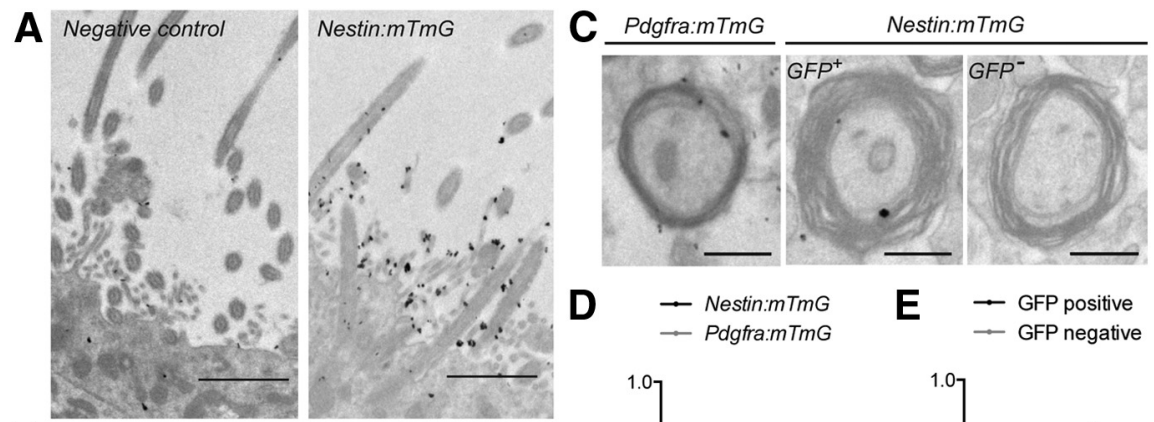

\section{.}
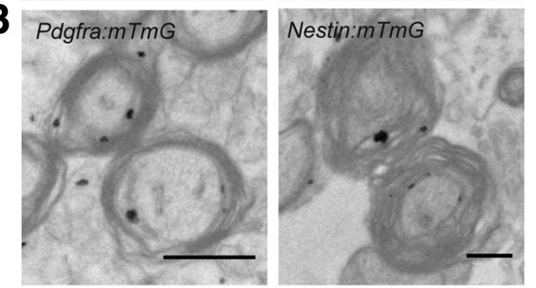

$\rightarrow$ Nestin:mTmG $\rightarrow$ Pdgfra:mTmG

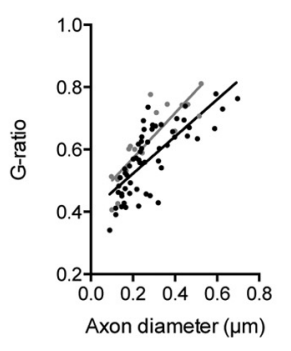

Figure 13. Ultrastructural localization of mGFP within regenerated myelin sheaths of the rostral CC revealed by immunoelectron microscopy. A, Immunogold labeling of mGFP detected in the cilia of NPCs in the SVZ of TAM/cuprizone Nestin:mTmG mice at the 6 week recovery time point. Compared with TAM/cuprizone Nestin:mTmG mice, significantly fewer gold particles (black dots) were detected in the brains of TAM/cuprizone NestinCreER ${ }^{T 2}$ single-transgenic mice that did not carry the $\mathrm{mTmG}$ allele, serving as a negative control. $\boldsymbol{B}$, Gold particles were detected in the POPC- or NPC-derived myelin sheaths in Pdgfra:mTmG or Nestin:mTmG mice, respectively. C, Electron micrographs of mGFP-labeled myelin identified in Pdgfra:mTmG or Nestin:mTmG mice, as well as unlabeled myelin in Nestin:mTmG mice. Note the differences in myelin thickness despite similar axon caliber and equal magnification. D, Scatterplot of g-ratio against axon diameter for mGFP-labeled myelinated axons in the region adjacent to the SVZ of Nestin:mTmG mice and in the midline region of Pdgfra:mTmG mice. Linear regression analysis of the lines of best fit revealed a significant difference in the $y$-intercepts $(p<0.0031)$, but no difference in the slopes $(p<0.36)$. $\boldsymbol{E}$, The equivalent scatterplot for mGFP-labeled and unlabeled axons in the region of the (C adjacent to the SVZ of Nestin:mTmG mice assessed at the 6 week recovery time point. Linear regression analysis of the lines of best fit revealed a significant difference in the $y$-intercepts $(p<0.0001)$, but no difference in the slopes $(p<0.66)$. Scale bars: $A, 1.5 \mu \mathrm{m} ; \boldsymbol{B}, \boldsymbol{C}, 500 \mathrm{~nm}$. Mean \pm SEM values are shown.

0.0031), linear regression analysis]. In addition, in Nestin:mTmG mice, gold-labeled $\mathrm{mGFP}^{+}$myelinated axons in the region of the CC adjacent to the SVZ had lower g-ratios than non-labeled $\left(\mathrm{mGFP}^{-}\right)$myelinated axons in the same region [Fig. 13E; significant difference in $y$-intercepts of lines of best fit $(p<0.0001)$, linear regression analysis]. Overall, our data suggest that NPCderived oligodendrocytes produce myelin rings that are thicker than those produced by pOPCs. As a consequence, average myelin thickness in regions that are remyelinated extensively by NPCs is indistinguishable from that of unchallenged controls.

\section{Discussion}

In this study, we identified that large numbers of NPCs are recruited to the demyelinated corpus callosum throughout its ros-

$\leftarrow$

Figure 12. Ultrastructural analysis of myelin integrity in the CC of wild-type cuprizone challenged versus control mice. $A$, Schematic diagram indicating regions of the $C($ examined ultrastructurally at the midline and adjacent to the SVZ in both the rostral and caudal segments. $\boldsymbol{B}$, Representative electron micrographs of myelinated, unmyelinated, and remyelinated axons within the rostral midline $C$, Left, Electron micrographs of the $C($ of mice examined at 6 weeks of recovery following a 6 week cuprizone challenge compared with control mice. Right, Mean g-ratios of myelinated axons of small diameter $(<0.5 \mu \mathrm{m})$, medium diameter $(0.5-0.8 \mu \mathrm{m})$, and large diameter $(>0.8 \mu \mathrm{m})$ quantified within the midline $C($ and in the region of the $C C$ adjacent to the SVZ within the rostral and caudal segments of control (black) and cuprizonechallenged mice (gray). Two-way ANOVA was used to compare g-ratios between control and cuprizone-challenged mice $\left({ }^{*} p<0.05,{ }^{* *} p<0.01,{ }^{* * *} p<0.001,{ }^{* * * *} p<0.0001\right)$. $\boldsymbol{D}$, Stacked histograms of myelinated (black) and unmyelinated (gray) axon densities in control versus cuprizone-challenged mice. Independent unpaired two-tailed Student's $t$ tests were used to compare differences in either the density of unmyelinated axons $\left({ }^{* * a} p<0.01\right)$ or the density of myelinated axons $\left({ }^{* \mathrm{~b}} p<0.05\right.$ ) between control and cuprizone-challenged mice. Scale bars: $B, 0.5 \mu \mathrm{m} ; \boldsymbol{C}, 4 \mu \mathrm{m}$. Mean \pm SEM values are shown.
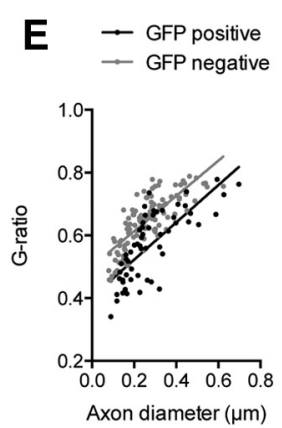

trocaudal axis, that this recruitment is most apparent adjacent to the SVZ and that the progeny of these cells contribute significantly to remyelination. We also identified that maturation of the NPCderived cells into myelinating oligodendrocytes occurs more robustly in the rostral than in the caudal segment of the CC. Within the rostral segment, the NPCderived cells also demonstrate a competitive advantage over pOPCs in their differentiative potential, whereas pOPCs are the predominant precursor that differentiates into oligodendrocytes within the medial and lateral CC, reflecting the limited migration potential of the NPCderived cells into these regions. Surprisingly, we also identified that pre-existing oligodendrocytes also appeared to contribute significantly to the re-emergent pool of $\mathrm{CC}^{+}$cells. Finally, we detected regional differences within the $\mathrm{CC}$ in the extent of remyelination and in the quality of myelin generated subsequent to the demyelinating insult.

These findings raise a number of important issues. First, the study provides evidence that the dynamics of POPC and NPC responsiveness to a demyelinating challenge within the CC differ. Although NPCs were recruited before the peak of overt demyelination, they did not participate in the generation of differentiated oligodendrocytes until after 4 weeks of cuprizone challenge. At the 4 week time point, most of the recruited NPCs $(60.2 \pm 7.5 \%)$ expressed both Sox10 and GFAP, suggestive of a "transitional" phenotype. At 6 weeks of recovery, the majority of NPCderived cells were defined as oligodendrocytes rather than astrocytes, the parsimonious view being that the transitional cells converted to oligodendrocytes. The alternative possibility is that there are two waves of migration of NPCs from the SVZ, with attrition of the first wave of cells occurring during the regenerative phase and with the second wave generating the oligodendroglia.

In contrast to the dynamics of recruitment of NPC-derived cells, the full complement of pOPC-derived oligodendrocytes was generated within the region of the CC adjacent to the SVZ, by the 4 week time point, except in the middle CC where the NPCderived contribution to regeneration was attenuated. Interestingly, this compromised capacity of pOPCs to contribute to differentiated oligodendrocytes beyond the fourth week of cuprizone challenge was selective to the region adjacent to the SVZ, such that numerous differentiated oligodendrocytes were generated from pOPCs in the medial and lateral callosal regions between this time point and 6 weeks of recovery. The parsimonious explanation for these findings is that there are regional differences in the callosal microenvironment that result in suppression of the differentiative potential of pOPCs resident adjacent to the SVZ. This suppression occurs in a region where and at a time when NPC-derived cells exhibit enhanced capacity to differentiate into oligodendrocytes. Collectively, these findings suggest that it is not only likely that the NPC-derived cells themselves provide the inhibitory stimulus but that there are differences in 
the factor responsiveness of pOPCs and nOPCs that have not, as yet, been identified. Independent of these differences in responsiveness of the two populations, the end result of the regenerative response is the re-establishment of a density of $\mathrm{CC}^{+}$cells throughout the CC that is equivalent to that identified in the healthy, quiescent state. This strongly suggests that this aspect of the regenerative process is controlled by elements within the callosal milieu that are unchanged by the demyelinative insult, the obvious candidate being the resident axonal population.

The overall contribution of NPC-derived oligodendrocytes to the remyelinating CC by 6 weeks recovery following cuprizone withdrawal was very significant, particularly adjacent to the SVZ. In the rostral CC, the majority $(63.8 \pm 7.9 \%)$ of newly generated oligodendrocytes were derived from NPCs rather than pOPCs across a region spanning $1800 \mu \mathrm{m}$. Importantly, our data also reveal that only a subpopulation of $\mathrm{CC}^{+}{ }^{+}$cells that re-emerge after 4 weeks of cuprizone challenge are newly generated, with many being pre-existing cells that must downregulate the CC1 antigen under early cuprizone challenge and subsequently reexpress the antigen at the 4 week time point. Thus, with regard to the population of newly generated oligodendrocytes defined by pOPC and NPC fate mapping, NPC-derived oligodendrocytes would actually represent $82.3 \pm 4.9 \%$ of newly generated oligodendrocytes within the rostral segment of the CC adjacent to the SVZ. This indicates that the region of the CC adjacent to the SVZ is much more permissive to oligodendrogenesis from NPCs than from pOPCs. Given the significant potential of the NPC population, the question as to what limits the remyelination capacity of the NPC-derived cells beyond the region adjacent to the SVZ is intriguing. Whether this is an intrinsic property of NPC-derived cells or whether this is a direct consequence of inhibition by pOPCs or their progeny that are resident within the medial and lateral CC is currently unclear.

To maximize the regenerative potential of NPCs in the context of demyelination, it will be necessary to identify the extrinsic signals responsible for the recruitment of NPCs into the CC, as well as their subsequent migration and differentiation. A number of extrinsic factors have been identified that can selectively promote the proliferation of NPCs toward an oligodendrogenic fate (Cate et al., 2010; Jablonska et al., 2010; Ortega et al., 2013). The CNTF has recently been shown to influence the migration of SVZ-derived NPCs in the context of lysolecithin-induced demyelination (Vernerey et al., 2013). Other factors that could either directly or indirectly influence the migration of both SVZderived NPCs and pOPCs include PDGF, which also promotes OPC proliferation (Vernerey et al., 2013) and potentiates remyelination after exposure to cuprizone (Woodruff et al., 2004; Murtie et al., 2005; Vana et al., 2007), EGF (Aguirre et al., 2007; Gonzalez-Perez et al., 2009), and members of the FGF family (Armstrong et al., 2002; Murtie et al., 2005). Levels of both FGF-2 and PDGF-AA are elevated in the brain tissue of humans with MS (Clemente et al., 2011) and in the cuprizone model (Gudi et al., 2011). Hepatocyte growth factor has also been shown to be released by microglia, and to stimulate the proliferation and migration of OPCs in experimental models of demyelination (Yan and Rivkees, 2002; Lalive et al., 2005).

The finding that oligodendrogenic NPCs recruited to the caudal CC exhibit markedly reduced capacity to generate fully mature myelinating oligodendrocytes is indicative of significant regional differences in oligodendrocyte maturation. Whereas similar numbers of NPCs were recruited from the SVZ into the adjacent demyelinating rostral and caudal CC at 4 weeks of cuprizone challenge, there were subsequent profound segmental differences in the capacity of NPCs to fully mature into myelinating oligodendrocytes. Notably, it was identified that the proportion and absolute numbers of Sox $10^{+} \mathrm{YFP}^{+}$populations that were also $\mathrm{CCl}^{+}$were highest in the rostral segment $(90.8 \%)$ and lowest in the caudal segment (31.4\%). Even more apparent was the overt failure of the NPC-derived oligodendroglia to fully differentiate into myelinating oligodendrocytes in the caudal segment, and this also applied to the pOPC population. This suggested the possibility of a maturation block, akin to what has been described in chronic MS lesions (Kuhlmann et al., 2008). Intriguingly, whereas pOPCs transition past this transient block by 14 weeks of cuprizone withdrawal, nOPCs remain under prolonged differentiation block at this time point. Collectively, these results demonstrate that there are significant regional differences in oligodendrocyte maturation and in the intrinsic properties of pOPCs and nOPCs. These regional and cell type-specific differences in oligodendroglial maturation could be due to several interacting variables. On the one hand, differences in local environmental signals within the rostrocaudal axis could account for regional differences in the efficiency of oligodendrogenesis. Notably, it has previously been demonstrated that caudal and midline regions of the $\mathrm{CC}$ are particularly vulnerable to cuprizone-induced demyelination (Stidworthy et al., 2003; Wu et al., 2008; Xie et al., 2010). On the other hand, it is formally possible that there are intrinsic differences in the maturation capacity of progenitors resident within the rostral as opposed to the caudal segment, and, in addition, our data provide evidence that oligodendrocyte maturation differs between pOPCs and nOPCs.

Our analysis of myelin integrity at the 6 week recovery time point revealed that g-ratios in the rostral and caudal SVZ were the same as those in unchallenged control mice. In contrast, in midline regions of both the rostral and caudal CC, in which pOPCs are the predominant precursor population, small myelinated axons exhibited increased g-ratios in cuprizone-challenged mice in comparison with controls. Direct examination by immunoelectron microscopy demonstrated that the axons myelinated by NPC-derived oligodendrocytes adjacent to the SVZ have lower g-ratios compared with axons myelinated by pOPC-derived cells at the midline. In addition, within the region of the CC adjacent to the SVZ, NPC-derived myelin was thicker than that produced by pOPCs. These data suggest that at the 6 week recovery time point the quality of myelin generated by pOPCs and nOPCs differs, with the latter responsible for generating myelin that is thicker and more akin to developmentally generated myelin. These data lead to the remarkable conclusion that lineage identity has a major influence upon the thickness of the myelin that oligodendrocytes produce. Thus, in agreement with another recent report (Powers et al., 2013), the long-held view that regenerated myelin is immutably thinner than myelin generated during normal postnatal development must now be re-examined. The finding also raises important questions for further investigation: first, what are the functional consequences of regenerative processes that lead to thin myelination as opposed to those that re-establish pre-existing myelin thickness; and second, if the consequences are important, how can the latter rather than the former response be promoted?

In summary, our data reveal that NPCs are major contributors to the generation of new myelinating oligodendrocytes in the context of demyelination, but on a regionally restricted basis. These findings have important implications for the development of therapies that specifically target NPCs for the treatment of demyelinating diseases such as multiple sclerosis. 


\section{References}

Aguirre A, Dupree JL, Mangin JM, Gallo V (2007) A functional role for EGFR signaling in myelination and remyelination. Nat Neurosci 10:9901002. CrossRef Medline

Armstrong RC, Le TQ, Frost EE, Borke RC, Vana AC (2002) Absence of fibroblast growth factor 2 promotes oligodendroglial repopulation of demyelinated white matter. J Neurosci 22:8574-8585. Medline

Arnett HA, Fancy SP, Alberta JA, Zhao C, Plant SR, Kaing S, Raine CS, Rowitch DH, Franklin RJ, Stiles CD (2004) bHLH transcription factor Olig1 is required to repair demyelinated lesions in the CNS. Science 306: 2111-2115. CrossRef Medline

Blakemore WF, Murray JA (1981) Quantitative examination of internodal length of remyelinated nerve fibres in the central nervous system. J Neurol Sci 49:273-284. CrossRef Medline

Cate HS, Sabo JK, Merlo D, Kemper D, Aumann TD, Robinson J, Merson TD, Emery B, Perreau VM, Kilpatrick TJ (2010) Modulation of bone morphogenic protein signalling alters numbers of astrocytes and oligodendroglia in the subventricular zone during cuprizone-induced demyelination. J Neurochem 115:11-22. CrossRef Medline

Clemente D, Ortega MC, Arenzana FJ, de Castro F (2011) FGF-2 and anosmin-1 are selectively expressed in different types of multiple sclerosis lesions. J Neurosci 31:14899-14909. CrossRef Medline

Dutta R, Trapp BD (2011) Mechanisms of neuronal dysfunction and degeneration in multiple sclerosis. Prog Neurobiol 93:1-12. CrossRef Medline

Ellis SL, Williams B, Asquith S, Bertoncello I, Nilsson SK (2009) An innovative triple immunogold labeling method to investigate the hemopoietic stem cell niche in situ. Microsc Microanal 15:403-414. CrossRef Medline

Gage FH (2000) Mammalian neural stem cells. Science 287:1433-1438. CrossRef Medline

Gledhill RF, McDonald WI (1977) Morphological characteristics of central demyelination and remyelination: a single-fiber study. Ann Neurol 1:552-560. CrossRef Medline

Gonzalez-Perez O, Romero-Rodriguez R, Soriano-Navarro M, GarciaVerdugo JM, Alvarez-Buylla A (2009) Epidermal growth factor induces the progeny of subventricular zone type B cells to migrate and differentiate into oligodendrocytes. Stem Cells 27:2032-2043. CrossRef Medline

Gudi V, Moharregh-Khiabani D, Skripuletz T, Koutsoudaki PN, Kotsiari A, Skuljec J, Trebst C, Stangel M (2009) Regional differences between grey and white matter in cuprizone induced demyelination. Brain Res 1283: 127-138. CrossRef Medline

Gudi V, Škuljec J, Yildiz Ö, Frichert K, Skripuletz T, Moharregh-Khiabani D, Voss E, Wissel K, Wolter S, Stangel M (2011) Spatial and temporal profiles of growth factor expression during CNS demyelination reveal the dynamics of repair priming. PLoS One 6:e22623. CrossRef Medline

Hesse A, Wagner M, Held J, Brück W, Salinas-Riester G, Hao Z, Waisman A, Kuhlmann T (2010) In toxic demyelination oligodendroglial cell death occurs early and is FAS independent. Neurobiol Dis 37:362-369. CrossRef Medline

Huang JK, Fancy SP, Zhao C, Rowitch DH, Ffrench-Constant C, Franklin RJ (2011) Myelin regeneration in multiple sclerosis: targeting endogenous stem cells. Neurotherapeutics 8:650-658. CrossRef Medline

Imayoshi I, Ohtsuka T, Metzger D, Chambon P, Kageyama R (2006) Temporal regulation of Cre recombinase activity in neural stem cells. Genesis 44:233-238. CrossRef Medline

Imayoshi I, Sakamoto M, Ohtsuka T, Takao K, Miyakawa T, Yamaguchi M, Mori K, Ikeda T, Itohara S, Kageyama R (2008) Roles of continuous neurogenesis in the structural and functional integrity of the adult forebrain. Nat Neurosci 11:1153-1161. CrossRef Medline

Irvine KA, Blakemore WF (2008) Remyelination protects axons from demyelination-associated axon degeneration. Brain 131:1464-1477. CrossRef Medline

Jablonska B, Aguirre A, Raymond M, Szabo G, Kitabatake Y, Sailor KA, Ming GL, Song H, Gallo V (2010) Chordin-induced lineage plasticity of adult SVZ neuroblasts after demyelination. Nat Neurosci 13:541-550. CrossRef Medline

Kuhlmann T, Miron V, Cui Q, Wegner C, Antel J, Brück W (2008) Differentiation block of oligodendroglial progenitor cells as a cause for remyelination failure in chronic multiple sclerosis. Brain 131:1749-1758. CrossRef Medline

Lalive PH, Paglinawan R, Biollaz G, Kappos EA, Leone DP, Malipiero U, Relvas JB, Moransard M, Suter T, Fontana A (2005) TGF-beta-treated microglia induce oligodendrocyte precursor cell chemotaxis through the HGF-c-Met pathway. Eur J Immunol 35:727-737. CrossRef Medline

Lee Y, Morrison BM, Li Y, Lengacher S, Farah MH, Hoffman PN, Liu Y, Tsingalia A, Jin L, Zhang PW, Pellerin L, Magistretti PJ, Rothstein JD (2012) Oligodendroglia metabolically support axons and contribute to neurodegeneration. Nature 487:443-448. CrossRef Medline

Lois C, Alvarez-Buylla A (1994) Long-distance neuronal migration in the adult mammalian brain. Science 264:1145-1148. CrossRef Medline

Matsushima GK, Morell P (2001) The neurotoxicant, cuprizone, as a model to study demyelination and remyelination in the central nervous system. Brain Pathol 11:107-116. Medline

Menn B, Garcia-Verdugo JM, Yaschine C, Gonzalez-Perez O, Rowitch D, Alvarez-Buylla A (2006) Origin of oligodendrocytes in the subventricular zone of the adult brain. J Neurosci 26:7907-7918. CrossRef Medline

Morell P, Barrett CV, Mason JL, Toews AD, Hostettler JD, Knapp GW, Matsushima GK (1998) Gene expression in brain during cuprizone-induced demyelination and remyelination. Mol Cell Neurosci 12:220-227. CrossRef Medline

Murtie JC, Zhou YX, Le TQ, Vana AC, Armstrong RC (2005) PDGF and FGF2 pathways regulate distinct oligodendrocyte lineage responses in experimental demyelination with spontaneous remyelination. Neurobiol Dis 19:171-182. CrossRef Medline

Muzumdar MD, Tasic B, Miyamichi K, Li L, Luo L (2007) A global doublefluorescent Cre reporter mouse. Genesis 45:593-605. CrossRef Medline

Nait-Oumesmar B, Decker L, Lachapelle F, Avellana-Adalid V, Bachelin C, Baron-Van Evercooren A (1999) Progenitor cells of the adult mouse subventricular zone proliferate, migrate and differentiate into oligodendrocytes after demyelination. Eur J Neurosci 11:4357-4366. CrossRef Medline

Nave KA (2010) Myelination and support of axonal integrity by glia. Nature 468:244-252. CrossRef Medline

Niu J, Mei F, Wang L, Liu S, Tian Y, Mo W, Li H, Lu QR, Xiao L (2012) Phosphorylated olig1 localizes to the cytosol of oligodendrocytes and promotes membrane expansion and maturation. Glia 60:1427-1436. CrossRef Medline

Oluich LJ, Stratton JA, Xing YL, Ng SW, Cate HS, Sah P, Windels F, Kilpatrick TJ, Merson TD (2012) Targeted ablation of oligodendrocytes induces axonal pathology independent of overt demyelination. J Neurosci 32: 8317-8330. CrossRef Medline

Ortega F, Gascón S, Masserdotti G, Deshpande A, Simon C, Fischer J, Dimou L, Chichung Lie D, Schroeder T, Berninger B (2013) Oligodendrogliogenic and neurogenic adult subependymal zone neural stem cells constitute distinct lineages and exhibit differential responsiveness to Wnt signalling. Nat Cell Biol 15:602-613. CrossRef Medline

Paxinos G, Franklin KBJ (2008) The mouse brain in stereotaxic coordinates, compact. San Diego, CA: Academic.

Petratos S, Gonzales MF, Azari MF, Marriott M, Minichiello RA, Shipham KA, Profyris C, Nicolaou A, Boyle K, Cheema SS, Kilpatrick TJ (2004) Expression of the low-affinity neurotrophin receptor, p75(NTR), is upregulated by oligodendroglial progenitors adjacent to the subventricular zone in response to demyelination. Glia 48:64-75. CrossRef Medline

Powers BE, Sellers DL, Lovelett EA, Cheung W, Aalami SP, Zapertov N, Maris DO, Horner PJ (2013) Remyelination reporter reveals prolonged refinement of spontaneously regenerated myelin. Proc Natl Acad Sci U S A 110:4075-4080. CrossRef Medline

Rivers LE, Young KM, Rizzi M, Jamen F, Psachoulia K, Wade A, Kessaris N, Richardson WD (2008) PDGFRA/NG2 glia generate myelinating oligodendrocytes and piriform projection neurons in adult mice. Nat Neurosci 11:1392-1401. CrossRef Medline

Spurr AR (1969) A low-viscosity epoxy resin embedding medium for electron microscopy. J Ultrastruct Res 26:31-43. CrossRef Medline

Srinivas S, Watanabe T, Lin CS, William CM, Tanabe Y, Jessell TM, Costantini F (2001) Cre reporter strains produced by targeted insertion of EYFP and ECFP into the ROSA26 locus. BMC Dev Biol 1:4. CrossRef Medline

Stidworthy MF, Genoud S, Suter U, Mantei N, Franklin RJ (2003) Quantifying the early stages of remyelination following cuprizone-induced demyelination. Brain Pathol 13:329-339. Medline

Tripathi RB, Rivers LE, Young KM, Jamen F, Richardson WD (2010) NG2 glia generate new oligodendrocytes but few astrocytes in a murine experimental autoimmune encephalomyelitis model of demyelinating disease. J Neurosci 30:16383-16390. CrossRef Medline

Vana AC, Flint NC, Harwood NE, Le TQ, Fruttiger M, Armstrong RC (2007) 
Platelet-derived growth factor promotes repair of chronically demyelinated white matter. J Neuropathol Exp Neurol 66:975-988. CrossRef Medline

Vernerey J, Macchi M, Magalon K, Cayre M, Durbec P (2013) Ciliary neurotrophic factor controls progenitor migration during remyelination in the adult rodent brain. J Neurosci 33:3240-3250. CrossRef Medline

Woodruff RH, Fruttiger M, Richardson WD, Franklin RJ (2004) Plateletderived growth factor regulates oligodendrocyte progenitor numbers in adult CNS and their response following CNS demyelination. Mol Cell Neurosci 25:252-262. CrossRef Medline

Wu QZ, Yang Q, Cate HS, Kemper D, Binder M, Wang HX, Fang K, Quick MJ, Marriott M, Kilpatrick TJ, Egan GF (2008) MRI identification of the rostral-caudal pattern of pathology within the corpus callosum in the cuprizone mouse model. J Magn Reson Imaging 27:446-453. CrossRef Medline

Xie M, Tobin JE, Budde MD, Chen CI, Trinkaus K, Cross AH, McDaniel DP,
Song SK, Armstrong RC (2010) Rostrocaudal analysis of corpus callosum demyelination and axon damage across disease stages refines diffusion tensor imaging correlations with pathological features. J Neuropathol Exp Neurol 69:704-716. CrossRef Medline

Yan H, Rivkees SA (2002) Hepatocyte growth factor stimulates the proliferation and migration of oligodendrocyte precursor cells. J Neurosci Res 69:597-606. CrossRef Medline

Young KM, Psachoulia K, Tripathi RB, Dunn SJ, Cossell L, Attwell D, Tohyama K, Richardson WD (2013) Oligodendrocyte dynamics in the healthy adult CNS: evidence for myelin remodeling. Neuron 77:873-885. CrossRef Medline

Zawadzka M, Rivers LE, Fancy SP, Zhao C, Tripathi R, Jamen F, Young K, Goncharevich A, Pohl H, Rizzi M, Rowitch DH, Kessaris N, Suter U, Richardson WD, Franklin RJ (2010) CNS-resident glial progenitor/ stem cells produce Schwann cells as well as oligodendrocytes during repair of CNS demyelination. Cell Stem Cell 6:578-590. CrossRef Medline 